\section{A NOVEL CARBON-BASED PROCESS FOR FLUE GAS CLEANUP}

Fifth Quarterly Technical Progress Report July 1 to September 30, 1992

Contract No. DE-AC21-91PC91345

Ms. Diane Revay Madden: DOE COR

\author{
S.K. Gangwal, Project Manager \\ Research Triangle Institute \\ Research Triangle Park, NC 27709 \\ (919) $541-8033$
}

P.L. Silveston, Co-Principal Investigator
University of Waterloo
Waterloo, Ontario, Canada N2L3G1
(519) $885-1211$, Ext. 2534

Submitted to:

U.S. Department of Energy

Pittsburgh Energy Technology Center P.O. Box 10940, Pittsburgh, PA 15236
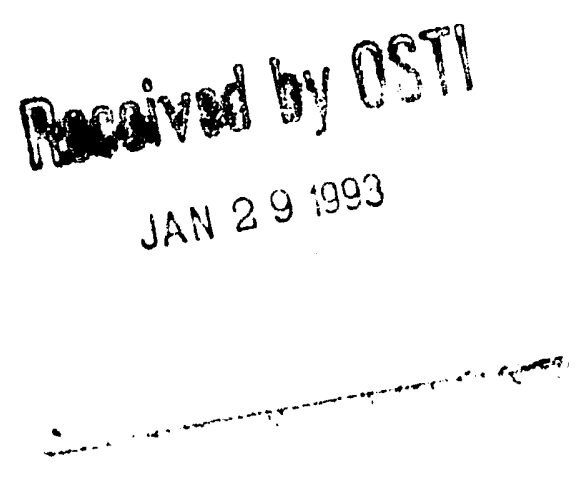

October 1992 


\section{TABLE OF CONTENTS}

Section

Page

List of Tables and Figures $\ldots \ldots \ldots \ldots \ldots \ldots \ldots \ldots$ ii

Abstract $\ldots \ldots \ldots \ldots \ldots \ldots \ldots \ldots \ldots$ iii

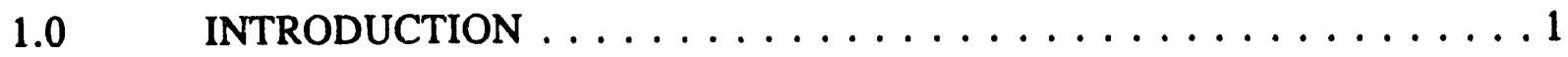

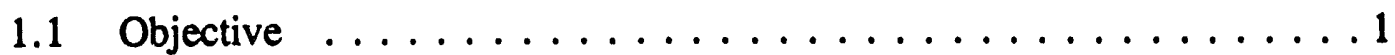

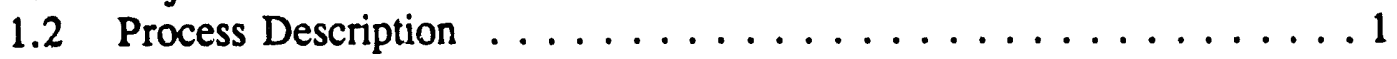

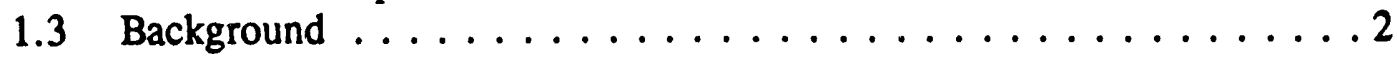

1.4 Project Scope/Schedule . . . . . . . . . . . . . . . 4

1.5 Measures of Success . . . . . . . . . . . . . . 6

2.0 WORK COMPLETED IN PREVIOUS QUARTERS $\ldots \ldots \ldots \ldots \ldots 7$

3.0 WORK COMPLETED IN PRESENT QUARTER $\ldots \ldots \ldots \ldots \ldots$

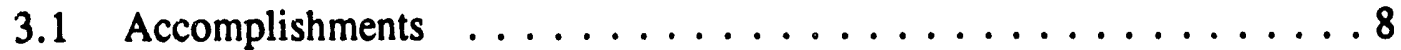

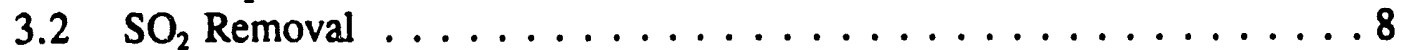

3.2.1 $\mathrm{SO}_{2}$ Removal Experiments at $21^{\circ} \mathrm{C} \ldots \ldots \ldots \ldots$

3.2.2 $\mathrm{SO}_{2}$ Removal Experiments at Higher Temperatures . . . . 8

$3.3 \mathrm{NO}_{\mathrm{x}}$ Removal . . . . . . . . . . . . . . . . . 10

3.4 Process Economic Evaluation $\ldots \ldots \ldots \ldots \ldots \ldots \ldots \ldots$

4.0 WORK PLANNED FOR NEXT QUARTER $\ldots \ldots \ldots \ldots \ldots$

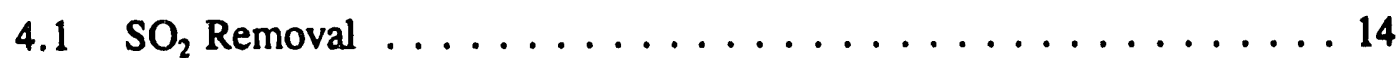

$4.2 \mathrm{NO}_{\mathrm{x}}$ Removal . . . . . . . . . . . . . . . . . 14

4.3 Process Evaluation . . . . . . . . . . . . . . . 14

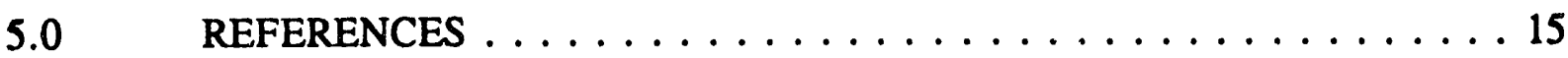

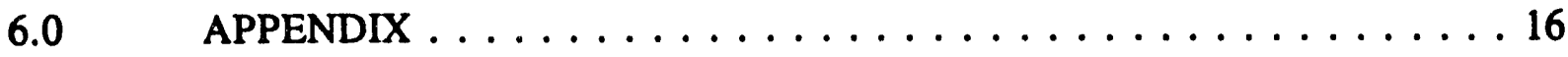




\section{LIST OF TABLES}

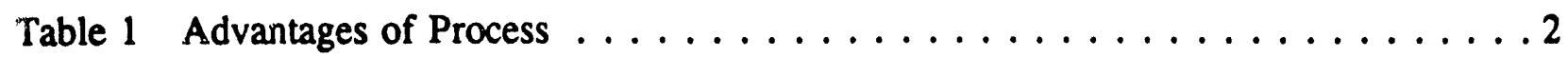

Table $2 \mathrm{SO}_{2}$ Removal Test Results $\left(37.22 \mathrm{~g}\right.$ of $\mathrm{MCCI}, 130^{\circ} \mathrm{C}, 1,475 \mathrm{scc} /\left(\mathrm{i}_{w}\right.$, h) Flue-Gas Containing 2,550 ppm SO $2,450 \mathrm{ppm} \mathrm{NO}, 10 \% \mathrm{CO}_{2}, 10 \% \mathrm{H}_{2} \mathrm{O}, 5 \% \mathrm{O}_{2}$, and Balance $\mathrm{N}_{2}, 200 \mathrm{cc} 4.32 \mathrm{~N} \mathrm{H}_{2} \mathrm{SO}_{4}$ flush after each cycle) . . . . . . . 10

Table 3 Feed Gas Composition for NO Removal Test of MCCII . . . . . . . . 11

Table 4 NO Removal with $\mathrm{MCCII}$ at $150^{\circ} \mathrm{C} \ldots \ldots \ldots \ldots \ldots \ldots$

Table 5 Process and Economic Assumptions $\ldots \ldots \ldots \ldots \ldots \ldots \ldots \ldots \ldots \ldots \ldots$

Table 6 RTI-Waterloo Process Economic Performance

(100 MW Power Plant, $65 \%$ Capacity Factor) $\ldots \ldots \ldots \ldots \ldots \ldots$

Table 7 Cost of $\mathrm{SO}_{2} / \mathrm{NO}_{\mathbf{x}}$ Removal (Mid $\left.1991 \$\right) \ldots \ldots \ldots \ldots \ldots$

\section{LIST OF FIGURES}

Figure 1 Flue gas cleanup process concept $\ldots \ldots \ldots \ldots \ldots \ldots \ldots$

Figure 2 Multistage activated carbon scrubbing process with pulsed liquid flow and cooling of the feed gas and reheating of the off-gas by heat recovery $\ldots \ldots \ldots \ldots \ldots \ldots \ldots \ldots$

Figure 3 Outlet Temperature and $\mathrm{SO}_{2}$ Concentration Versus Run Time (MCCI Catalyst, Inlet Temperature $80^{\circ} \mathrm{C} \ldots \ldots \ldots \ldots \ldots \ldots \ldots$ 


\section{ABSTRACT}

The objective of this project is to demonstrate the preliminary technical and economic feasibility of a novel carbon-based process for removal of at least $95 \% \mathrm{SO}_{2}$ and at least $75 \% \mathrm{NO}_{\mathrm{x}}$ from coal combustion flue gas. In the process, flue gas leaving the electrostatic precipitator (ESP) is passed through a trickle bed of activated carbon catalyst employing a periodic flush of low strength sulfuric acid. The $\mathrm{SO}_{2}$ is oxidized to $\mathrm{SO}_{3}$ and removed as medium strength sulfuric acid. The $\mathrm{SO}_{2}$-free flue gas is then mixed with $\mathrm{NH}_{3}$, and the $\mathrm{NO}_{x}$ in the gas is subjected to selective catalytic reduction (SCR) to $\mathrm{N}_{2}$ over a fixed bed of activated carbon catalyst.

The project is being carried out over 23 months (June 4, 1991, to April 30, 1993). The experimental work is divided between Research Triangle Institute (RTI) and the University of Waterloo (Waterloo). RTI will primarily conduct the $\mathrm{NO}_{\mathrm{x}}$ removal studies, whereas Waterloo will conduct most of the $\mathrm{SO}_{2}$ removal studies. The ultimate goal of the project is to demonstrate that the process can reduce the cost of electricity by $20 \%$ over conventional SCR/flue gas desulfurization (FGD) processes.

In the previous four quarters, a detailed project management plan was prepared describing the experimental setup, work plan, and test plan. The experimental system was completed for $\mathrm{SO}_{2}$ conversion at Waterloo and for $\mathrm{NO}_{x}$ conversion at RTI. Shakedown experiments were completed. Scoping studies at Waterloo with the BPL carbon showed that periodic flushing could only achieve up to $40 \% \mathrm{SO}_{2}$ removal with one bed. The $\mathrm{SO}_{2}$ removal factorial experiments were begun at Waterloo with the BPL carbon at $21^{\circ} \mathrm{C} . \mathrm{SO}_{2}$ removal was also tested at RTI on two catalysts at $80^{\circ} \mathrm{C}$. It was shown that the BPL carbon could remove over $95 \% \mathrm{SO}_{2}$ at $21^{\circ} \mathrm{C}$ but would require several beds at a space velocity in each bed of about $1500 \mathrm{scc} /(\mathrm{cc} \cdot \mathrm{h})$ to reduce $\mathrm{SO}_{2}$ from $2,500 \mathrm{ppm}$ to $100 \mathrm{ppm}$. A modified carbon catalyst (MCCI) tested at RTI showed $99 \% \mathrm{SO}_{2}$ removal at $80^{\circ} \mathrm{C}$ and 1,400 $\mathrm{scc} /(\mathrm{cc} \cdot \mathrm{h})$. The modified carbon catalyst also demonstrated removal of more than $80 \% \mathrm{NO}_{\mathrm{x}}$ at around $140^{\circ} \mathrm{C}$ and $1,400 \mathrm{scc} /(\mathrm{cc} \cdot \mathrm{h})$.

The $\mathrm{NO}_{\mathrm{x}}$ removal performance of two additional modified carbon catalysts MCCII and MCCIII) was studied. MCCII showed $\mathrm{NO}_{x}$ removal efficiency which was similar to that observed for MCCI. However, MCCIII was considerably less active for $\mathrm{NO}_{x}$ removal. $\mathrm{SO}_{2}$ removal experiments with NO present in the feed gas were performed with $\mathrm{MCCI}$. $\mathrm{SO}_{2}$ removal efficiency was consistently about $98 \%$ over each of 10 cycles and was very similar to that observed earlier with no NO present in the feed. Finally, a preliminary economic evaluation of the process was performed and a project review meeting was held. The economic evaluation showed that the RTI-Waterloo process was competitive with SCR/FGD and other combined $\mathrm{SO}_{2} / \mathrm{NO}_{\mathbf{x}}$ removal processes.

In the present quarter, further tests of MCCI were performed for $\mathrm{SO}_{2}$ removal with NO in the feed gas, except the reactor was operated at $130^{\circ} \mathrm{C}$ (instead of $80^{\circ} \mathrm{C}$ during previous tests). Tests were also performed with MCCII for NO removal with nominally 100 ppm $\mathrm{SO}_{2}$ in the feed gas. Papers were presented at the AIChE meeting in Minneapolis and the Contractor's Review Meeting in Pittsburgh. 


\subsection{INTRODUCTION}

\subsection{OBJECTIVE}

The objective of this project is to demonstrate the preliminary technical and economic feasibility of a novel carbon-based process for removal of at least $95 \% \mathrm{SO}_{2}$ and at least $75 \%$ $\mathrm{NO}_{\mathrm{x}}$ from coal combustion flue gas. The process is based on the demonstrated ability of activated carbons to catalyze $\mathrm{SO}_{2}$ oxidation and $\mathrm{NO}_{\mathrm{x}}$ reduction below $150^{\circ} \mathrm{C}$.

\subsection{PROCESS DESCRIPTION}

The process concept is shown in Figure 1. The hot flue gas leaves the electrostatic precipitator (ESP) at $\sim 150^{\circ} \mathrm{C}$ and enters a recuperative gas-gas heat exchanger, employing a bed of ceramic balls, to cool the flue gas for $\mathrm{SO}_{2}$ removal and simultaneously heat the cold flue gas for $\mathrm{NO}_{\mathrm{x}}$ removal. The gas leaving the exchanger enters a series of two to three activated carbon trickle-bed catalytic reactors at approximately $100^{\circ} \mathrm{C}$ to remove the $\mathrm{SO}_{2}$ and convert it to medium strength sulfuric acid. The essentially $\mathrm{SO}_{2}$-free gas from the last trickle bed goes through the exchanger to the $\mathrm{NO}_{\mathrm{x}}$ converter. The required amount of $\mathrm{NH}_{3}$ (typically in an $\mathrm{NO}_{\mathbf{x}} / \mathrm{NH}_{3}$ mol ratio of 1 ) is mixed with the flue gas prior to the activated carbon catalyst bed. The advantages of the proposed process concept compared to currently available $\mathrm{SO}_{2} / \mathrm{NO}_{\mathbf{x}}$ processes are summarized in Table 1 .

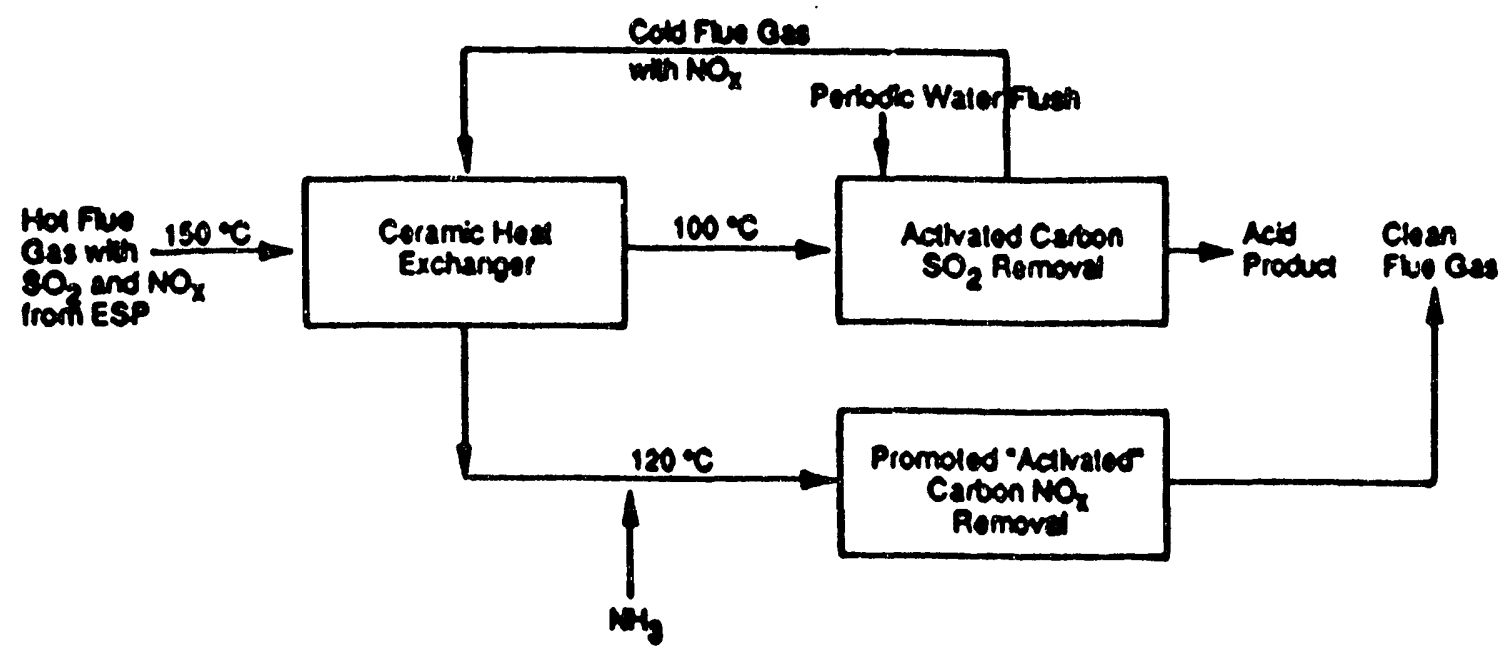

Figure 1. Flue gas cleanup process concept. 
Table 1. Advantages of Process

\section{$\mathrm{SO}_{2}$ Removal}

- Easier retrofit

- No waste product

Low temperature

- Simple regeneration

- Periodic operation

NO Removal

- High catalyst life

- Low salt/SO $\mathrm{SO}_{3}$ formation
- Downstream of ESP where space is more readily available

- Sulfuric acid is potentially marketable

- Reduced equipment stress, nonenergy intensive, no hazards including carbon combustion

- No carbon loss

- Low pressure drop, concentrated sulfuric acid
- Low temperature operation in the absence of $\mathrm{SO}_{2}$ and particles significantly increases catalyst life

- Due to complete $\mathrm{SO}_{\mathrm{x}}$ removal upstream, the acid dew point of the gas is very low and salt formation is avoided

\subsection{BACKGROUND}

The $\mathrm{SO}_{2}$ removal process proposed herein is based on the well-known lowtemperature catalytic properties of activated carbon, but uses a novel periodically flushed trickle bed to produce a strong acid and a low level of $\mathrm{SO}_{2}$ in the gas discharge. Hartman et al. (1971) and Hartman and Coughlin (1972) provide a detailed description of the mechanism of $\mathrm{SO}_{2}$ oxidation $\left[\mathrm{SO}_{2}+(1 / 2) \mathrm{O}_{2} \rightarrow \mathrm{SO}_{3}\right.$ or $\left.\mathrm{SO}_{2}+(1 / 2) \mathrm{O}_{2}+\mathrm{H}_{2} \mathrm{O} \rightarrow \mathrm{H}_{2} \mathrm{SO}_{4}\right]$ over activated carbon. The $\mathrm{SO}_{3}$ formed does not desorb spontaneously at low temperature. It is desorbed with water as sulfuric acid. Sulfuric acid, however, suppresses the ionization of dissolved sulfur dioxide and solubility of oxygen so that countercurrent contacting must be used to continue the reaction at an appreciable rate. Acid formation is accomplished in our process by periodic flushing, which results in a lower pressure drop and more concentrated sulfuric acid than achievable by continuous flushing. 
Work in the co-principal investigator's laboratory at the University of Waterloo (Waterloo) (Haure et al., 1989) has shown the feasibility of the process. With a single bed and periodic water flushing ( 0.9 min water flow in every 90 -min cycle), a time averaged acid concentration of nearly 0.2 molar was achieved. Based on this result, a conceptual process employing acid recycle to produce medium strength sulfuric acid is shown in Figure 2. $\mathrm{SO}_{2}$ is absorbed from the gas phase and converted into sulfuric acid by two to three in-line periodically liquid-pulsed beds of carbon. Typically water, dilute strength acid or medium strength acid flows through them for 2 to $4 \mathrm{~min}$ in every 30- to 40-min cycle. The gas phase flows through the beds continuously. Co-current flow is employed so that high superficial velocities can be used without flooding. Two to three in-line, co-current trickle beds of sufficient depth should provide complete removal of $\mathrm{SO}_{2}$. The recycling arrangement passes the strongest acid through the bed, treating the richest gas, and thereby produces medium strength acid as a product. The gas-gas heat exchanger brings the flue gas leaving the third bed to the desired temperature for catalytic $\mathrm{NO}_{x}$ removal, which is the second part of our process, as shown previously in Figure 1.

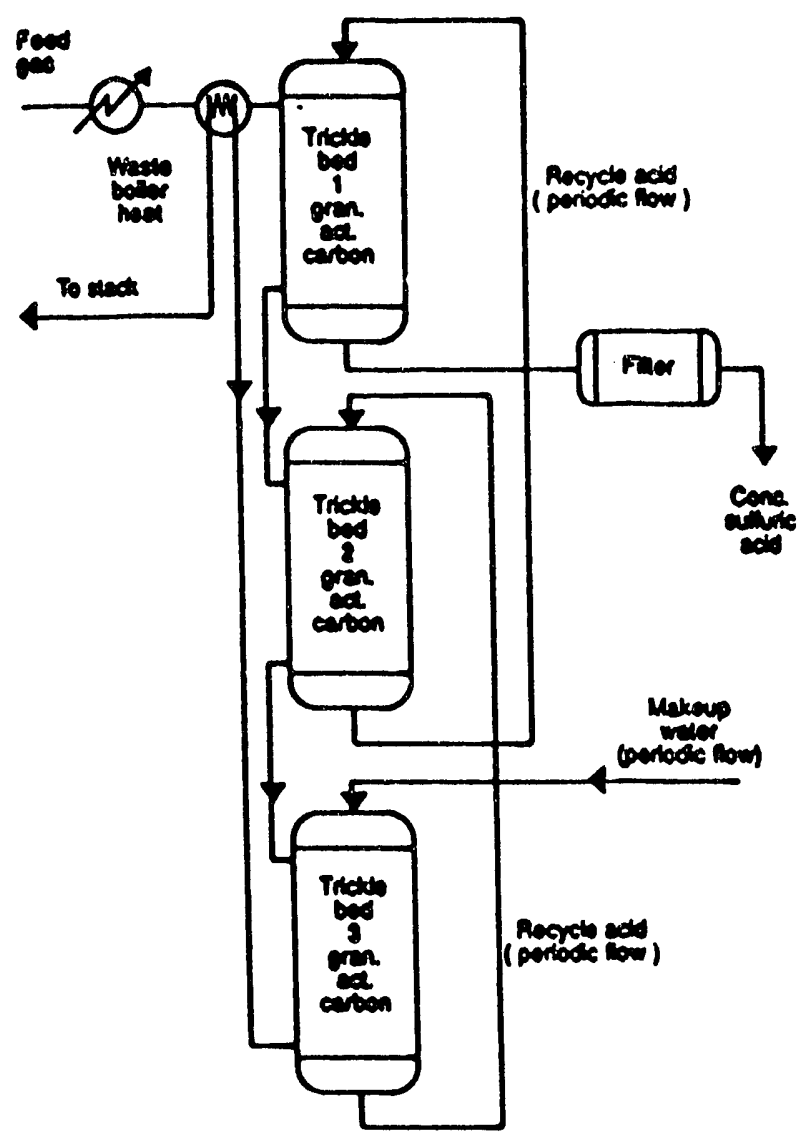

Figure 2. Multistage activated carbon scrubbing process with pulsed liquid flow and cooling of the feed gas and reheating of the off-gas by heat recovery. 
$\mathrm{NO}_{\mathbf{x}}$ is reduced in a separate reactor at $120^{\circ} \mathrm{C}$ using $\mathrm{NH}_{3}$ after the $\mathrm{SO}_{2}$ has been removed, and the $\mathrm{N}_{2}$ and $\mathrm{H}_{2} \mathrm{O}$ are vented to the stack. One possible reaction is $4 \mathrm{NH}_{3}+$ $4 \mathrm{NO}+\mathrm{O}_{2} \rightarrow 4 \mathrm{~N}_{2}+6 \mathrm{H}_{2} \mathrm{O}$, although many others are possible. Many catalysts for the $\mathrm{NH}_{3}-\mathrm{NO}$ reaction are reported in the literature (commercially practiced in selective catalytic reduction (SCR) technology using vanadium-based catalysts). However, many of these catalysts are inactive at $120^{\circ} \mathrm{C}$. A comprehensive unpublished review of the literature by the principal investigators indicated that activated carbon or "coke" catalysts are the only catalysts with the potential to carry out the reaction at $120^{\circ} \mathrm{C}$. Such catalysts are commercially used in the Mitsui process, which claims some $85 \% \mathrm{NO}_{x}$ removal at $130^{\circ} \mathrm{C}$. A number of studies (Kusakabe et al., 1988; Kuehl et al., 1986; Seki et al., 1975; U.S. Patent 4,194,373; Kareko et al., 1988) corroborate that activated carbons are active low temperature catalysts for the $\mathrm{NO}-\mathrm{NH}_{3}-\mathrm{O}_{2}$ and $\mathrm{NO}-\mathrm{NH}_{3}$ reactions. These studies further suggest that activated carbons promoted with very small quantities of group VIII transition metals (particularly platinum) should be considered.

\subsection{PROJECT SCOPE/SCHEDULE}

The novel carbon-based process to be studied has the potential to provide a technically sound and economically attractive solution to flue gas cleanup. The $\mathrm{SO}_{2}$ removal experiments will be carried out in the apparatus of Haure et al. (1989) at Waterloo, modified to handle dilute to medium strength sulfuric acid and temperatures up to $100^{\circ} \mathrm{C}$. The questions to be addressed in the research include:

- What acid concentrations are attainable by periodic pulsing and acid recycle?

- What is the pressure drop as a function of time during a cycle of no liquid flow to liquid flow?

- What is the optimum size of the granular activated carbon?

- What is the optimum pulse length to prevent poisoning (as occurring in steadystate operation) of the activated carbon?

- What is the optimal temperature of operation?

- What will be the effect and fate of $\mathrm{NO}_{\mathbf{x}}$ ?

The experimental parameters investigated will include carbon type, size, bed depth, gas composition, liquid composition, gas velocity, liquid velocity, cycle time, flush time and gas temperature. To reduce the number of variables, the carbon used will be the BPL carbon (Calgon Corporation) which was found to be the most active in the previous study. Because the experiments are expected to be short, a large number of parametric experiments will be carried out to prove feasibility and obtain data to permil a process evaluation. 
The $\mathrm{NO}_{\mathrm{x}}$ removal experiments will be carried out at Research Triangle Institute (RTI). The experiments will be geared toward demonstrating $>75 \% \mathrm{NO}_{\mathrm{x}}$ removal from offgases expected from the activated carbon $\mathrm{SO}_{2}$ conversion process. The principle variables considered will include carbon type (BPL carbon, 0.1 to $1 \% \mathrm{Pt}$ on carbon, and three others), temperature $\left(100\right.$ to $\left.150^{\circ} \mathrm{C}\right)$, and space velocity $[5,000$ to $20,000 \mathrm{scf} /(\mathrm{cf} \cdot \mathrm{h})]$. A proper $\mathrm{N}_{2}$ balance will be carried out in each experiment and slip of $\mathrm{NH}_{3}$ and $\mathrm{NO} / \mathrm{NO}_{\mathrm{x}}$ in the reaction products will be measured. The effect of traces of $\mathrm{SO}_{2}$ up to $250 \mathrm{ppmv}$ on $\mathrm{NO}_{\mathrm{x}}$ conversion will be examined.

Based on the experimental data, technical and economic evaluation of the process for $1 \mathrm{MW}$ and $100 \mathrm{MW}$ plants will be carried out. The technical evaluation shall determine the degree of $\mathrm{SO}_{2}$ and $\mathrm{NO}_{\mathrm{x}}$ removal that may be achieved in full-scale plants using the data collected in the controlled laboratory experiments. Economic evaluation will determine the cost of our process on unit power generation basis. The predicted cost will be compared with the cost of the conventional limestone flue gas desulfurization (FGD)/SCR system. If cost is at least $20 \%$ less for our process, our process will be considered for scaleup in future investigations.

The work to be carried out is divided into the following tasks:

Task

Task 1:

Program Definition

(RTI and Waterloo)

Task 2: $\quad$ Experimental

2.1: $\quad \mathrm{SO}_{2}$ Removal (Waterloo)

2.2: $\quad \mathrm{NO}_{\mathrm{x}}$ Removal (RTI)

Task 3: $\quad$ Process Evaluation (RTI)
Schedule

June 4, 1991, to July 31,1991

August 1, 1991, to February 28, 1993

May 1, 1992, to April 30, 1993

Task 1 (Program Definition) entails preparation of a detailed Project Management Plan describing a detailed work plan for the entire project and detailed test plans describing the experimental work. In Task 2 (Experimental), facilities will be constructed and experiments will be carried out per the approved Project Management Plan. $\mathrm{SO}_{2}$ removal experiments will be carried out at Waterloo under the supervision of Dr. P.L. Silveston. $\mathrm{NO}_{\mathbf{x}}$ removal experiments will be carried out at RTI under the supervision of Dr. S.K. Gangwal. In Task 3 (Process Evaluation), technical and economic evaluation of the process for $1 \mathrm{MW}$ and $100 \mathrm{MW}$ plants will be carried out by RTI.

It will be important to maintain a high degree of communication between Waterloo and RTI to ensure success of the project. The communication will be maintained by weekly conference calls. Also, an RTI investigator will travel to Waterloo at least twice during the 
project to review their experimental progress. Similarly, a Waterloo investigator will travel to RTI at least twice during the project.

\subsection{MEASURES OF SUCCESS}

The targets that we hope to achieve during the course of our experiments are:

- $95 \%$ or greater removal of $\mathrm{SO}_{2}$,

- Production of at least 2 molar sulfuric acid,

- Pressure drop of at most $30 \mathrm{in}$. in the $\mathrm{SO}_{2}$ removal process,

- $75 \%$ or greater removal of $\mathrm{NO}_{x}$, and

- 25 ppmv or less $\mathrm{NH}_{3}$ slip.

The experimental data would also indicate how to achieve further improvements in the above targets. The project is designed to prove the technical and economic feasibility of the process and provide sufficient data to permit a preliminary process evaluation. The ultimate test of the success of the project will be whether the process can reduce the cost of electricity over conventional FGD/SCR processes by $20 \%$. 


\subsection{WORK COMPLETED IN PREVIOUS QUARTERS}

The accomplishments in the previous quarters were as follows:

- A paper was published and presented at the Seventh Annual Coal Preparation, Utilization, and Environmental Control Contractors' Conference sponsored by the U.S. Department of Energy/Pittsburgh Energy Technology Center (DOE/PETC);

- Task 1 was completed. A detailed Project Management Plan was prepared describing the work plan, experimental apparatus, experimental test plan/sequence, milestone schedule, cost plan, key personnel plan, project management structure, and measures of success;

- Task 2 was begun. The assembly of experimental apparatus and shakedown tests at Waterloo and RTI were completed with the exception of the installation of a continuous $\mathrm{SO}_{2}$ analyzer.

- Sufficient catalysts were procured for the $\mathrm{SO}_{2}$ removal experiments at Waterloo and for the $\mathrm{NO}_{\mathrm{x}}$ removal experiments at RTI.

- A number of catalyst screening tests were completed for $\mathrm{SO}_{2}$ and $\mathrm{NO}_{x}$ conversion. It was shown that $75 \% \mathrm{NO}_{\mathrm{x}}$ conversion was possible on selected carbon catalysts.

- A continuous $\mathrm{SO}_{2}$ analyzer system was commissioned at Waterloo and $\mathrm{SO}_{2}$ removal factorial experiments with BPL carbon at $21^{\circ} \mathrm{C}$ began.

- $\mathrm{SO}_{2}$ removal was also tested at RTI on a modified carbon catalyst and a CarboTech carbon at a higher temperature $\left(80^{\circ} \mathrm{C}\right)$.

- $\mathrm{NO}_{\mathrm{x}}$ removal was tested at RTI on a number of carbon-based catalysts.

- The modified carbon catalyst (MCCI) tested at RTI consistently removed 99\% $\mathrm{SO}_{2}$ over multiple cycles at $80^{\circ} \mathrm{C}$ and $1,400 \mathrm{scc} /(\mathrm{cc} \cdot \mathrm{h})$.

- The modified carbon catalyst also demonstrated removal of more than $80 \% \mathrm{NO}_{\mathrm{x}}$ at about $140^{\circ} \mathrm{C}$ and $1,400 \mathrm{scc} /(\mathrm{cc} \cdot \mathrm{h})$.

- A second modified carbon catalyst (MCCII) showed $\mathrm{NO}_{\mathrm{x}}$ removal efficiency which was similar to that observed for MCCI.

- $\mathrm{SO}_{2}$ removal efficiency using $\mathrm{MCCI}$ with $\mathrm{NO}$ in the feed gas was consistently about $98 \%$ over 10 cycles.

- An economic evaluation showed that the RTI-Waterloo process is competitive with $\mathrm{SCR} / \mathrm{FGD}$ and other combined $\mathrm{SO}_{2} / \mathrm{NO}_{\mathrm{x}}$ removal processes. 


\subsection{WORK COMPLETED IN PRESENT QUARTER}

\subsection{ACCOMPLISHMENTS}

The accomplishments in the present quarter are as follows:

- Tests of $\mathrm{MCCI}$ at $130^{\circ} \mathrm{C}$ were performed for $\mathrm{SO}_{2}$ removal with $\mathrm{NO}$ in the feed gas.

- Tests of MCCII were performed for NO removal with nominally $100 \mathrm{ppm} \mathrm{SO}_{2}$ in the feed.

- The economic evaluation work was expanded to include cost sensitivity with respect to catalyst cost, catalyst life, acid strength, and number of beds for the $\mathrm{SO}_{2}$ removal part of the process.

\section{$3.2 \mathrm{SO}_{2}$ REMOVAL}

\subsection{1 $\mathrm{SO}_{2}$ Removal Experiments at $21^{\circ} \mathrm{C}$}

See Appendix 1.

\subsection{2 $\mathrm{SO}_{2}$ Removal Experiments at Higher Temperatures}

The same modified carbon catalyst $(\mathrm{MCCl})$ which had previously been used for tests of $\mathrm{SO}_{2}$ removal at $80^{\circ} \mathrm{C}$ with $\mathrm{NO}$ present in the feed was tested $\mathrm{t} 130^{\circ} \mathrm{C}$. The purpose of this test was to examine the effect of reactor temperature on $\mathrm{SO}_{2}$ removal in the early part of a cycle. As described in the previous quarterly report, when the reactor was operated at $80^{\circ} \mathrm{C}$, the $\mathrm{SO}_{2}$ removal initially was greater than $95 \%$, but would decrease to about $40 \%$ and then return to greater than $95 \%$ over a $1-2$ hour period, before beginning to decrease again. A plot which illustrates this behavior is shown in Figure 3. It is believed that the lower reactor outlet temperature is caused by water evaporation following the cold liquid flush. This appears to reduce the $\mathrm{SO}_{2}$ removal during the time in which the bed is heating to the inlet temperature of $80^{\circ} \mathrm{C}$.

To test whether this behavior could be prevented, a 3-cycle test was performed on MCCI at $130^{\circ} \mathrm{C}$. The results of this test, shown in Table 2, indicate that $\mathrm{SO}_{2}$ removal at the beginning of exposure is greater than 97 , but that breakthrough occurs in about $1 / 3$ of the time observed previously in $80^{\circ} \mathrm{C}$ tests. However, the period of time in which conversion is greater than $95 \%$ is about the same as that observed at $80^{\circ} \mathrm{C}$ and the percent $\mathrm{SO}_{2}$ removal does not decrease in the early part of the cycle as observed before. Operating the reactor at $130^{\circ} \mathrm{C}$ offers the advantage of sustained high $\mathrm{SO}_{2}$ removal efficiency with a breakthrough time which is feasible for the periodic flush process. Since the overall breakthrough time 


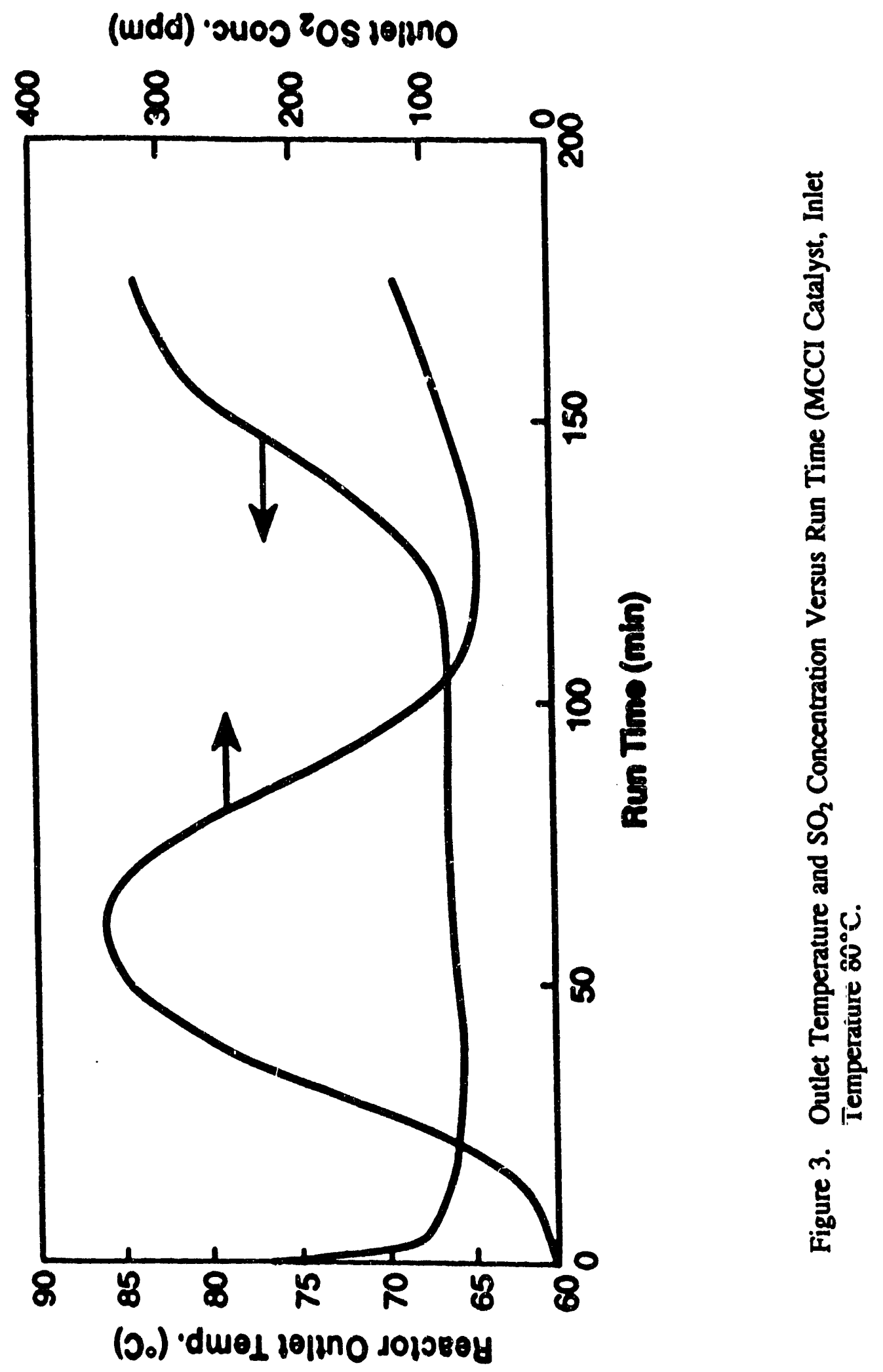


Table 2. $\mathrm{SO}_{2}$ Removal Test Results $\left(37.22 \mathrm{~g}\right.$ of $\mathrm{MCCI}, 130^{\circ} \mathrm{C}, 1,475 \mathrm{scc} /(\mathrm{cc} \cdot \mathrm{h})$ FlueGas Containing 2,550 ppm SO ${ }_{2}, 450 \mathrm{ppm} \mathrm{NO}, 10 \% \mathrm{CO}_{2}, 10 \% \mathrm{H}_{2} \mathrm{O}, 5 \% \mathrm{O}_{2}$, and Balance $\mathrm{N}_{2}, 200 \mathrm{cc} 4.32 \mathrm{~N} \mathrm{H}_{2} \mathrm{SO}_{4}$ flush after each cycle)

\begin{tabular}{cccc}
\hline Cycle & $\begin{array}{c}\text { Breakthrough time } \\
\text { (h) } \\
\text { (at 5\%) }\end{array}$ & $\begin{array}{c}\text { Percent } \mathrm{SO}_{2} \\
\text { Removal }\end{array}$ & $\mathrm{SO}_{2}$ Converted, (g) \\
\hline & 1.75 & 99.6 & 3.83 \\
2 & 0.8 & 97.8 & 1.67 \\
3 & 1.1 & 99.7 & 2.32 \\
\hline \hline
\end{tabular}

however is shorter, the results suggest that the optimum temperature may be closer to $100^{\circ} \mathrm{C}$ with respect to both capacity and $\mathrm{SO}_{2}$ removal efficiency.

\subsection{NO, REMOVAL}

A batch of MCCII which had been used previously for $\mathrm{SO}_{2}$ removal tests was used to test $\mathrm{NO}$ removal with nominally $100 \mathrm{ppm} \mathrm{SO}{ }_{2}$ in the feed gas. The feed gas composition is summarized in Table 3.

The reactor was operated at a temperature of $150^{\circ} \mathrm{C}$ and a space velocity of 1480 $\mathrm{scc} /(\mathrm{cc} \cdot \mathrm{h})$. Results of a 24 hour deactivation test are shown in Table 4 . Based on these results, there did appear to be some deactivation of the catalyst over the 24 hour period, as conversion decreased from $79 \%$ to $66 \%$ however the reason for the cycling up at 18 hours is not clear. The catalyst needs to be run longer to firm up this data.

Before $\mathrm{SO}_{2}$ was introduced into the feed gas at the beginning of the test, the NO conversion was near $100 \%$. When the $\mathrm{SO}_{2}$ was added, the increase in the outlet NO concentration was equivalent to the feed gas $\mathrm{SO}_{2}$ concentration. This suggests that ammonia preferentially reacts with $\mathrm{SO}_{2}$, thus making it unavailable for reduction of NO. This explains the need for a higher $\mathrm{NH}_{3} / \mathrm{NO}$ ratio in the feed (1.57) compared with what was needed previously (1.26) to achieve $>75 \%$ NO reduction with no $\mathrm{SO}_{2}$ present. However, the overall process shows capability for $100 \% \mathrm{SO}_{2}$ removal and this may need to be traded with any potential catalyst deactivation. If $\left(\mathrm{NH}_{4}\right)_{2} \mathrm{SO}_{4}$ formation on the catalyst is the cause of deactivtion, then it may be possible to wash it off, to reactivate the catalyst. A moving-bed system might be employed in this scenario. 
Table 3. Feed Gas Composition for NO Removal Test of MCCII

\begin{tabular}{cc}
\hline \hline & Feed Concentration \\
\hline & \\
& \\
$\mathrm{NO}_{2}$ & $500 \mathrm{ppm}$ \\
$\mathrm{SO}_{2}$ & $106 \mathrm{ppm}$ \\
$\mathrm{NH}_{3}$ & $783 \mathrm{ppm}$ \\
$\mathrm{Steam}$ & $11.7 \%$ \\
$\mathrm{CO}_{2}$ & $10 \%$ \\
$\mathrm{O}_{2}$ & $5 \%$ \\
\hline
\end{tabular}

Table 4. NO Removal with $\mathrm{MCCII}$ at $150^{\circ} \mathrm{C}$

Time On Stream, hrs. Percent NO Conversion

4279

$6 \quad 78$

$8 \quad 71$

$10 \quad 69$

$12 \quad 68$

$14 \quad 68$

$16-64$

$18 \quad 74$

$20 \quad 74$

$22 \quad 66$

$24 \quad 66$ 


\subsection{Process Economic Evaluation}

Based on the results to date, a preliminary engineering and economic evaluation of the RTI-Waterloo process was conducted for a $100 \mathrm{MW}$ electric power plant burning a $2.8 \%$ sulfur coal. The process and economic assumptions are shown in Table 5. The Electric Power Research Institute (EPRI) technical assessment guide (TAG) method was used for the calculations. An economic sensitivity analysis of the process with respect to the $\mathrm{SO}_{2}$ conversion reactor variables (no. of stages, catalyst cost, and catalyst life) was performed. In addition, sensitivity of the economics was performed for the acid product strength. It was assumed that the $\mathrm{SO}_{2}$ reactors would yield 32 weight $\% \mathrm{H}_{2} \mathrm{SO}_{4}$ and this was further concentrated using an external evaporator to 77.67 and 93.2 weight \% $\mathrm{H}_{2} \mathrm{SO}_{4}$. The capital and levelized cost for this analysis is shown in Table 6 and compared to conventional and emerging $\mathrm{SO}_{2} / \mathrm{NO}_{\mathrm{x}}$ removal processes in Table 7. Even considering that the scale used for the RTI-Waterloo process was $100 \mathrm{MW}$ as opposed to $500 \mathrm{MW}$ for the other processes, the RTI-Waterloo process was competitive with the other processes.

Table 5. Process and Economic Assumptions

\begin{tabular}{|c|c|c|}
\hline Power Plant Capacity & -- & $100 \mathrm{MW}, 65 \%$ Capacity Factor \\
\hline Coal Type & -- & Illinois $\# 6,2.8 \%$ Sulfur \\
\hline Flue-Gas Composition & - & $\begin{array}{l}72.6 \% \mathrm{~N}_{2}, 4.5 \% \mathrm{O}_{2}, 12.6 \% \mathrm{CO}_{2}, 10 \% \mathrm{H}_{2} \mathrm{O}, 2300 \\
\text { ppm } \mathrm{SO}_{2}, 530 \mathrm{ppm} \mathrm{NO} \times\end{array}$ \\
\hline $\mathrm{SO}_{2}$ Conversion & - & 2 or 3 Stages, $10,000 \mathrm{~h}^{-1}$ in each stage \\
\hline $\mathrm{NO}_{\mathrm{x}}$ Conversion & -- & $\begin{array}{l}1 \text { Stage, } 3500 \mathrm{~h}^{-1}, \mathrm{NH}_{3} / \mathrm{NO}_{\mathrm{x}}=1.35 \text {, Promoted Carbon } \\
\text { Catalyst, } \$ 20 / \mathrm{lb}\end{array}$ \\
\hline Acid Storage & -- & 24 hours \\
\hline Value of $32 \% \mathrm{H}_{2} \mathrm{SO}_{4}$ & -- & $\$ 24 /$ ton \\
\hline Value of $77.67 \% \mathrm{H}_{2} \mathrm{SO}_{4}$ & -- & $\$ 58 /$ ton \\
\hline Value of $93 \% \mathrm{H}_{2} \mathrm{SO}_{4}$ & -- & $\$ 70 /$ ton \\
\hline Cost of $\mathrm{NH}_{3}$ & -- & $\$ 150 /$ ton \\
\hline Dollars & -- & Mid 1991 \\
\hline
\end{tabular}


Table 6. RTI-Waterloo Process Economic Performance (100 MW Power Plant, 65\% Capacity Factor)

\begin{tabular}{cccccc}
\hline & $\mathrm{SO}_{2}$ Conversion & & $\begin{array}{c}\text { Acid Product } \\
\text { Strength }\end{array}$ & $\begin{array}{c}\text { Capital } \\
\text { Cost }\end{array}$ & $\begin{array}{c}\text { Levelized } \\
\text { Cost }\end{array}$ \\
$\begin{array}{ccccc}\text { Stages } \\
(--)\end{array}$ & $\begin{array}{c}\text { Catalyst } \\
\text { Cost } \\
(\$ / \mathrm{lb})\end{array}$ & $\begin{array}{c}\text { Catalyst } \\
\text { Life } \\
(\text { Yrs })\end{array}$ & (Weight \%) & $(\$ / \mathrm{kW})$ & $(\mathrm{Mils} / \mathrm{kWh})$ \\
\hline & & & & & \\
3 & 20 & 3 & 32 & 179 & 8.2 \\
2 & 20 & 3 & 32 & 162 & 6.8 \\
3 & 20 & 3 & 77.67 & 188 & 9.0 \\
3 & 20 & 6 & 77.67 & 188 & 7.3 \\
2 & 20 & 6 & 93.67 & 171 & 6.4 \\
3 & 20 & 6 & 93.2 & 188 & 8.3 \\
2 & 20 & 2 & 77.67 & 171 & 7.4 \\
3 & 3 & 2 & 93.2 & 169 & 6.3 \\
3 & 3 & & & & 8.0 \\
\hline
\end{tabular}

Table 7. Cost of $\mathrm{SO}_{2} / \mathrm{NO}_{\mathbf{x}}$ Removal (Mid 1991 \$)

\begin{tabular}{lccc}
\hline \multicolumn{1}{c}{ Process } & MW & $\begin{array}{c}\text { Capital Cost } \\
(\$ / \mathrm{kW})\end{array}$ & $\begin{array}{c}\text { Levelized } \\
\text { Cost } \\
(\text { Mils/kWh) }\end{array}$ \\
& & & \\
\hline & 500 & 200 & 8.8 \\
Conventional SGD/SCR & 500 & 170 & 7.8 \\
Advanced FGD/SCR & 500 & $215 / 260 / 300$ & $8 / 11.8 / 17$ \\
NOXSO & 500 & $330 / 375 / 430$ & $8.8 / 10.4 / 13$ \\
SNOX & 500 & $310 / 400 / 440$ & $9 / 13.2 / 15.3$ \\
E-Beam & 100 & 162 to 188 & 6.3 to 9.0 \\
RTI/Waterloo & & & \\
\hline
\end{tabular}

Estimates except for RTI/Waterloo process from Cichanowicz, et al., Engineering Evaluation of Combined $\mathrm{NO}_{\mathbf{x}} / \mathrm{SO}_{2}$ Controls, 1991 . 


\subsection{WORK PLANNED FOR NEXT QUARTER}

\section{1 $\mathrm{SO}_{2}$ Removal}

Tests of the unmodified carbon corresponding to MCCI will be performed. Tests of a different modified carbon catalyst (MCCIV) will also be performed.

\subsection{NO Removal}

Tests of the unmodified carbon corresponding to MCCI will be performed.

\subsection{Process Evaluation}

A detailed economic evaluation report will be prepared. 


\subsection{REFERENCES}

Hartman, M., and R.W. Couglin. 1972. Chem. Eng. Sci. 127:867-880.

Harman, M., J. Polek, and R.W. Coughlin. 1971. Chem. Eng. Prog. Symp. Ser., No. 115, 67:7-22.

Haure, P., R.R. Hudgins, and P.L. Silveston. 1989. AIChE Journal, 35:1437.

Kareko, K., Y. Nakahigashi, and K. Nagata. 1988. Carbon, 26(3):327-333.

Keuhl, H., E. Richter, K. Knoblauch, and H. Juentgn. 1986. Carbon '86, BerganForschung, Essen, Germany, pp. 351-353.

Kusakube, K., M. Karhima, S. Morook, and K. Shigeharu. 1988. Fuel, 67(5):714-718.

Seki, M., Y. Sakurai, and K. Yoshida. 1975. Am. Chem. Soc. Div. Eng. Chem. Reprints: 15(2), Chicago Meeting, August 24-29, pp. 28-31. 
APPENDIX 1

UNIVERSITY OF WATERLOO

QUARTERLY REPORT 


\subsection{WORK COMPLETED IN PRESENT QUARTER (July - October 1992)}

\subsection{ACCOMPLISHMENTS}

- Completed first set of factorial experiments

- Demonstrated that $2 \mathrm{~N}$ sulfuric acid strengths can be achieved

- Calculated bed depth and pressure drop for $95 \% \mathrm{SO}_{2}$ removal

\section{$1.2 \mathrm{SO}_{2}$ REMOVAL EXPERIMENTS AT $21^{\circ} \mathrm{C}$}

These experiments were carried out at the University of Waterloo. The equipment was run at $21^{\circ} \mathrm{C}$ with a gas mixture of $2500 \mathrm{ppm} \mathrm{SO}_{2}, 5 \% \mathrm{O}_{2}, 15 \% \mathrm{CO}_{2}$, and the balance $\mathrm{N}_{2}$.

The factorial design method that was started last quarter to determine which of the five operating variables would most affect $\mathrm{SO}_{2}$ removal (meaning removal of $\mathrm{SO}_{2}$ from the gas), $\mathrm{SO}_{2}$ conversion (meaning percentage of total $\mathrm{SO}_{2}$ passing through the reactor converted to sulfuric acid), acid strength of product (maximum sulfuric acid, minimum sulfurous acid) and pressure drop has been completed. At this time however I can not complete an analysis for bed pressure drop $(\Delta \mathrm{P})$ because part way through the experiments a change was made in order to more accurately measure the bed $\Delta \mathrm{P}$. Table 1 shows the range and the variables studied. A total of 16 experiments were required with 8 replicates in order to estimate the experimental variance. This is a $2^{5-1}$ factorial design of resolution $\mathrm{V}$. Resolution $\mathrm{V}$ means that single factor interactions are confounded with four factor interactions, and two factor and three factor interactions are confounded.

It should be noted that the flushing medium (deionized water, $2.0 \mathrm{~N}$ sulfuric acid) is a blocked variable for convenience. The settings of the five different variables for each of the 24 experiments and the results are illustrated in Table 2. Where 2 experiments at a single set of conditions were done, in order to estimate the experimental variance, the results were averaged and are displayed as a single result.

Table 1: Levels of Variables studied in Factorial Experiments

\begin{tabular}{|c|c|c|}
\hline Variables & Low Value "-" & High Value "+" \\
\hline 1-Space Velocity $\left(\mathrm{V}_{1}\right)$ & $1000 \mathrm{cc}^{\circ} \mathrm{cc}^{-1} \cdot \mathrm{hr}^{-1}$ & 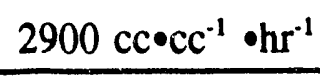 \\
\hline $\begin{array}{l}\text { 2-Liquid Velocity }\left(\mathrm{V}_{\mathrm{g}}\right) \\
\text { (superficial) }\end{array}$ & $0.2 \mathrm{~cm} \cdot \mathrm{s}^{-1}$ & $1.0{\mathrm{~cm} \cdot \mathrm{s}^{-1}}^{-1}$ \\
\hline 3-Period $(\tau)$ & 5 minutes & 30 minutes \\
\hline 4-Flush Duration(D) & 0.5 minutes & 3 minutes \\
\hline 5-Flush Liquid(A) & Deionized Water & $2.0 \mathrm{~N} \mathrm{H}_{2} \mathrm{SO}_{4}$ \\
\hline
\end{tabular}



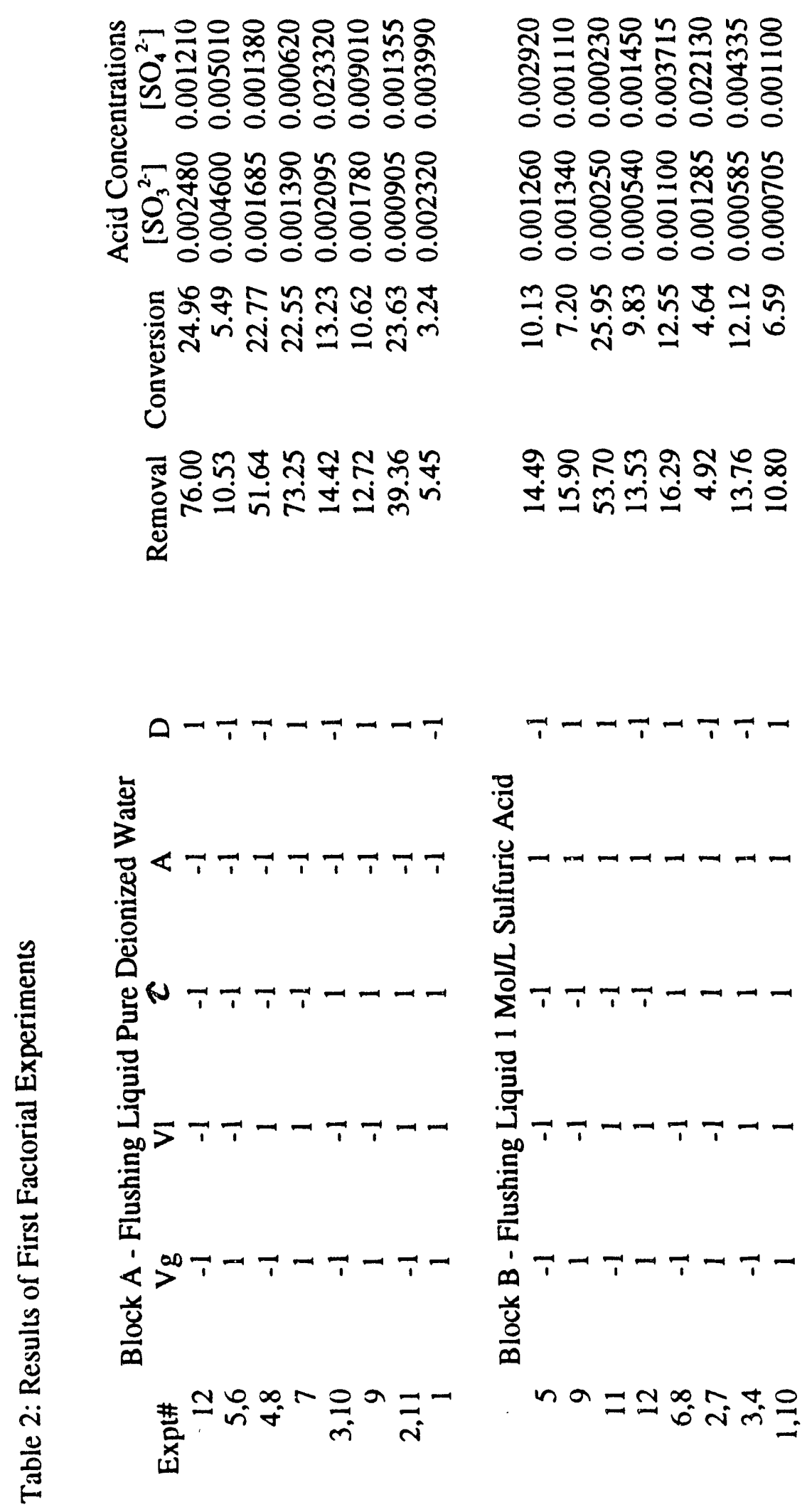
The main effect of each variable was calculated by using the Yate's Algorithm. The main effect is the average of the response at the high value of the variable and the average at the low value of the variable. The significance of an effect was then determined by using a statistical significance test after calculating the estimated standard error of an effect from the replicates.

The conclusions of the initial factorial design are as follows:

\section{Removal}

\section{Single Factor Effects}

$\mathrm{V}_{\mathrm{g}} \quad$ - increasing the gas velocity had a detrimental effect on the removal. The average effect of the increase in the gas velocity can be seen in Figure 1.

$\mathrm{V}_{1} \quad$ - increasing the superficial liquid velocity increases removal. (Figure 2)

D - increasing the flush duration increases the removal. (Figure 3) The effects of $V_{1}$ and $D$ indicate an increase in contact between the liquid and gas phases resulting in higher removals

$\tau \quad$ - increasing the period reduces the removal. (Figure 4)

This effect indicates that the catalyst surface becomes saturated with adsorbed $\mathrm{SO}_{2}$ and can no longer remove additional $\mathrm{SO}_{2}$ from the gas phase

A - increasing the liquid phase acid strength reduces removal. (Figure 5)

Two Factor Effects

$\tau, \mathrm{D}$ - the optimum removal is obtained by using a short period with a long flush duration

$\tau, \mathrm{A} \quad$ - the optimum removal is obtained with a short period and minimum acid strength of the liquid phase, however as the liquid phase acid strength increases (due to recycling of liquid phase), the period should be increased in order to maintain the removal.

\section{Conversion}

$\mathrm{V}_{\mathrm{g}} \quad$ - This is the only factor affecting the conversion. Increasing the gas velocity reduces the conversion. (Figure 6) 


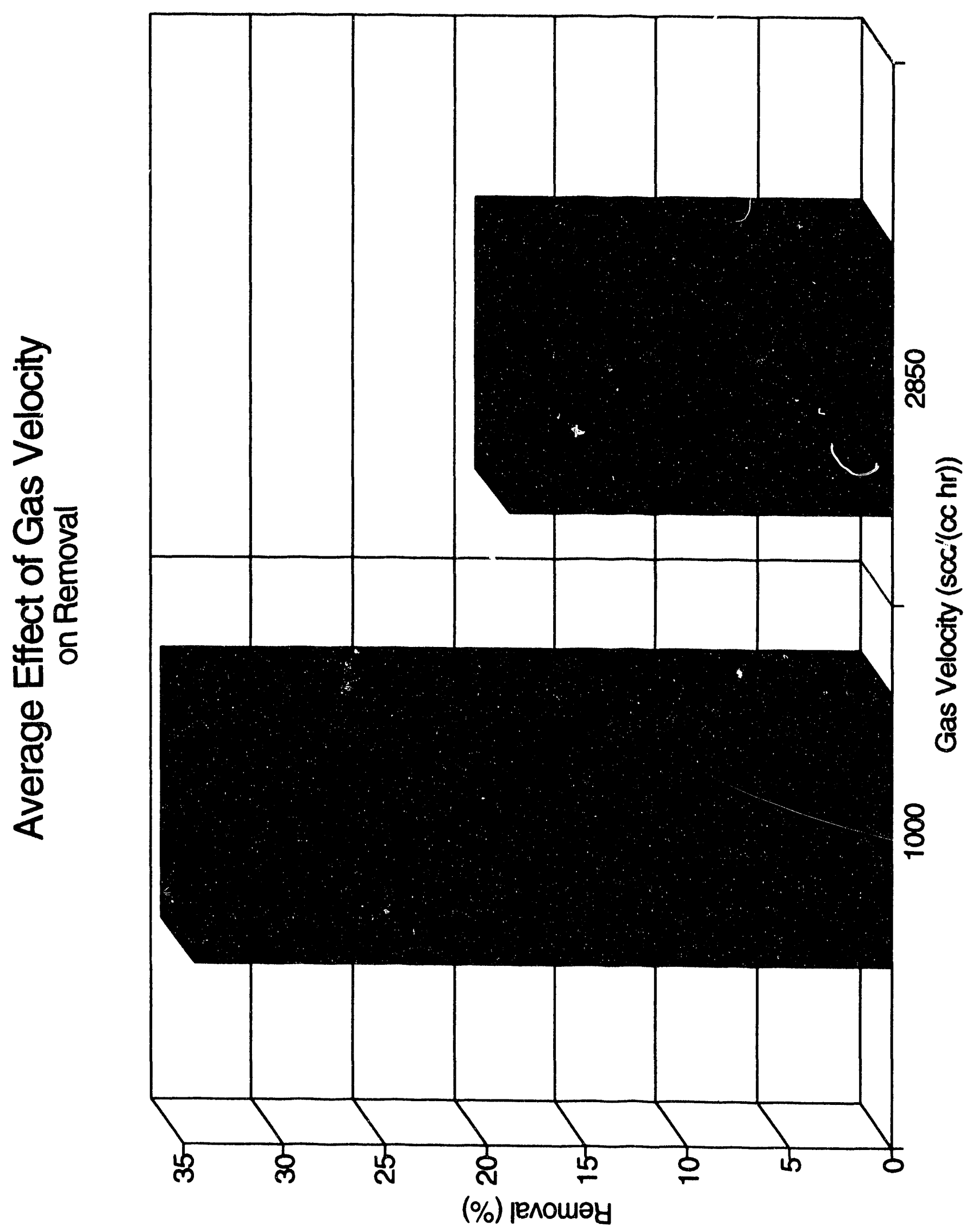




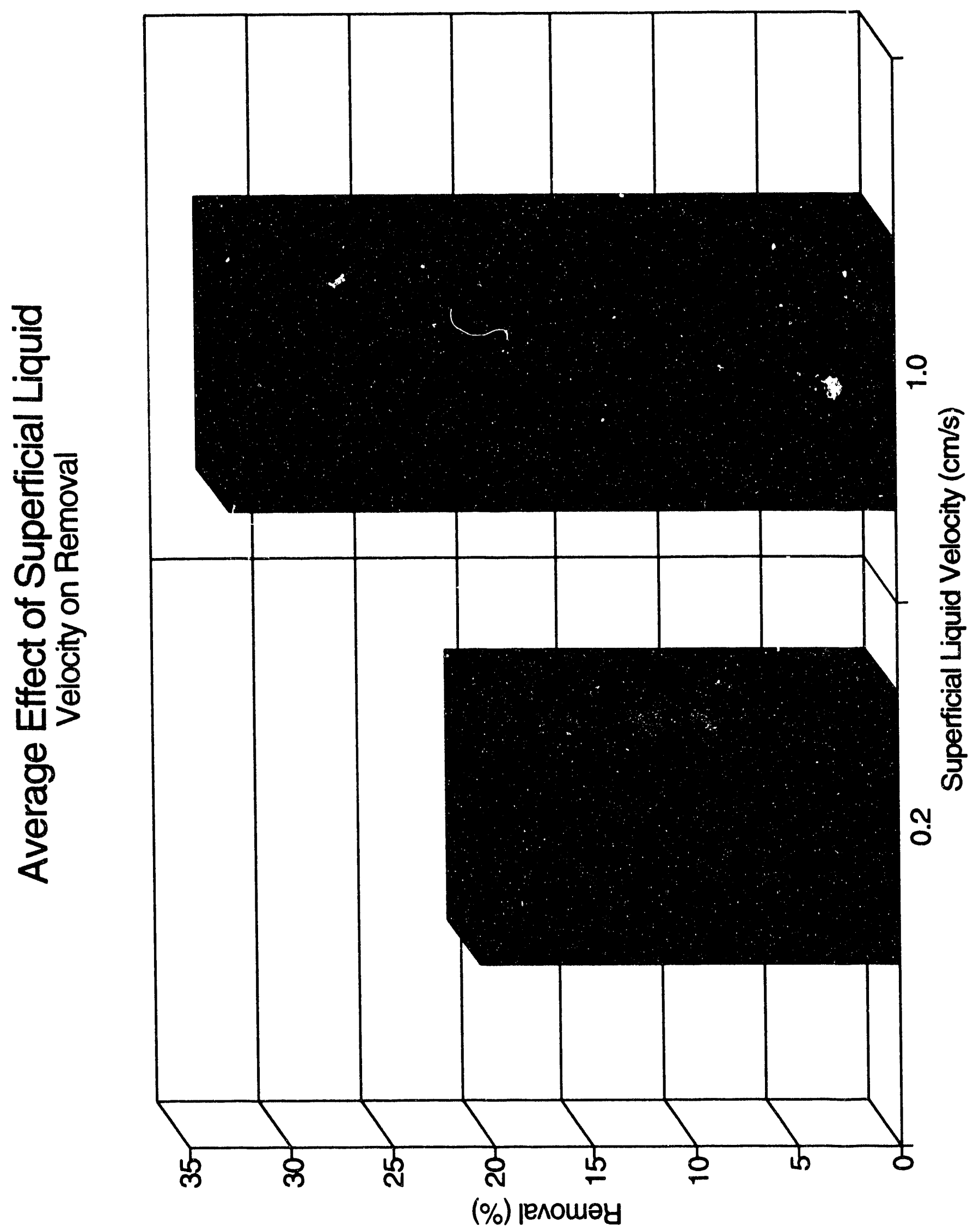




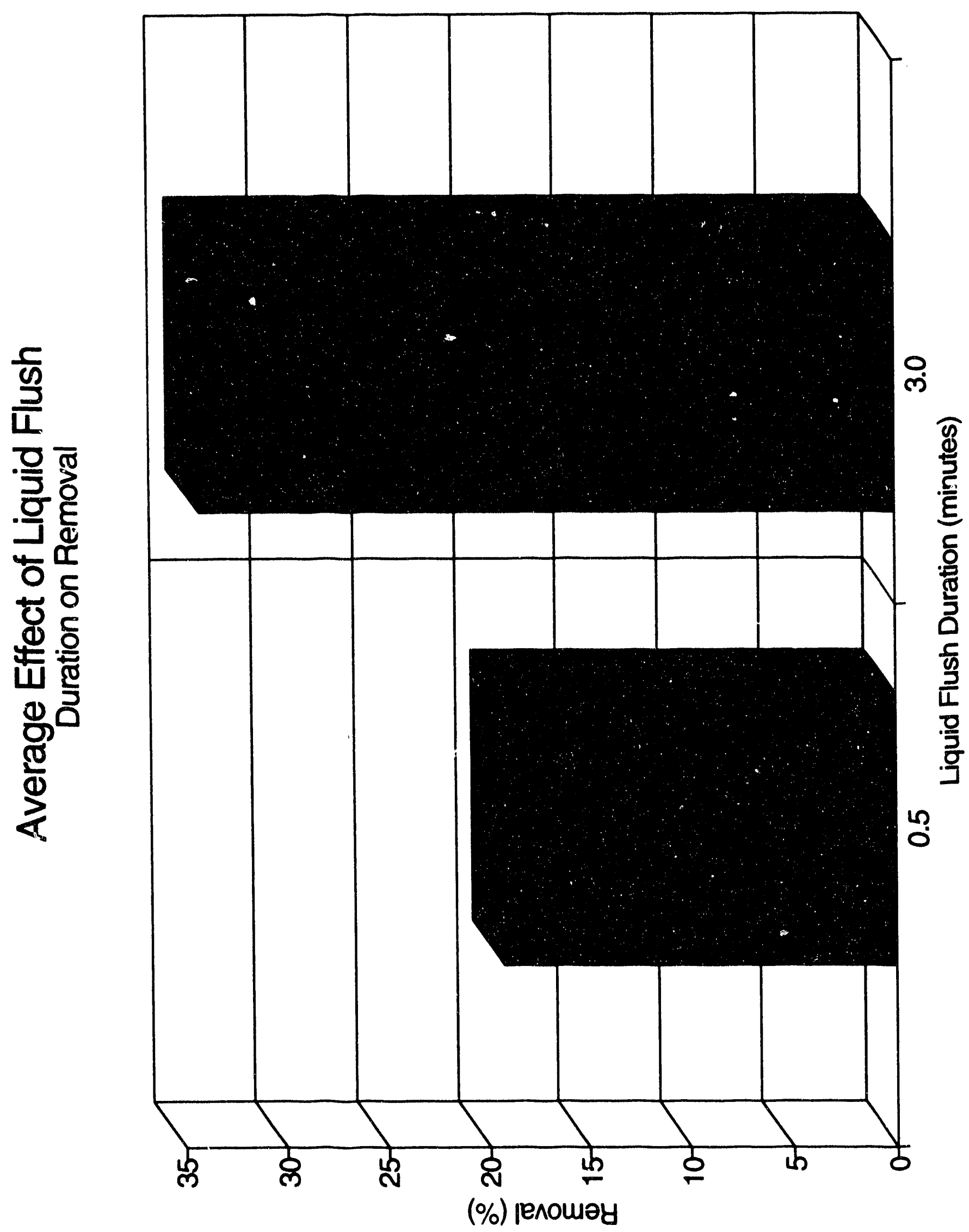




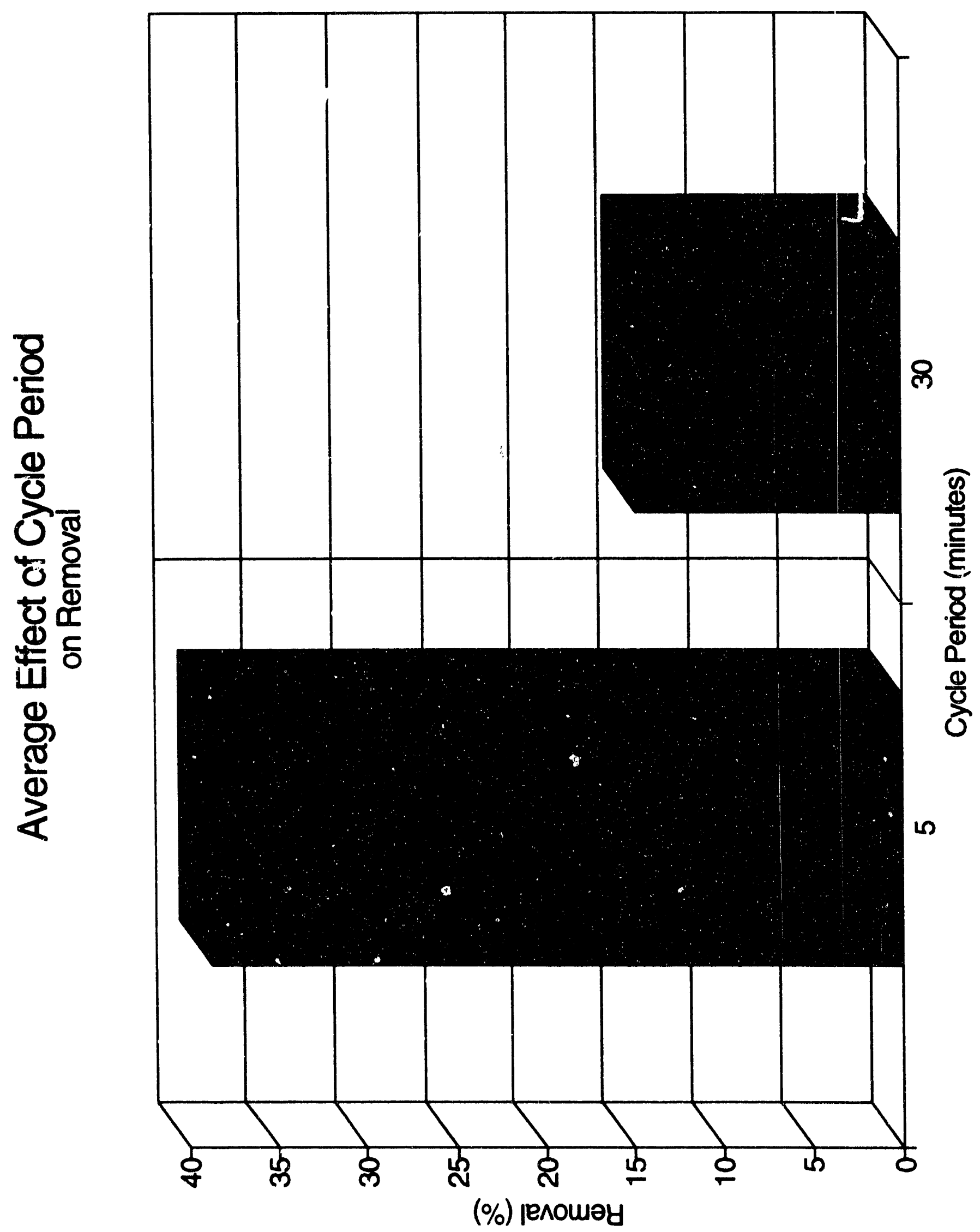




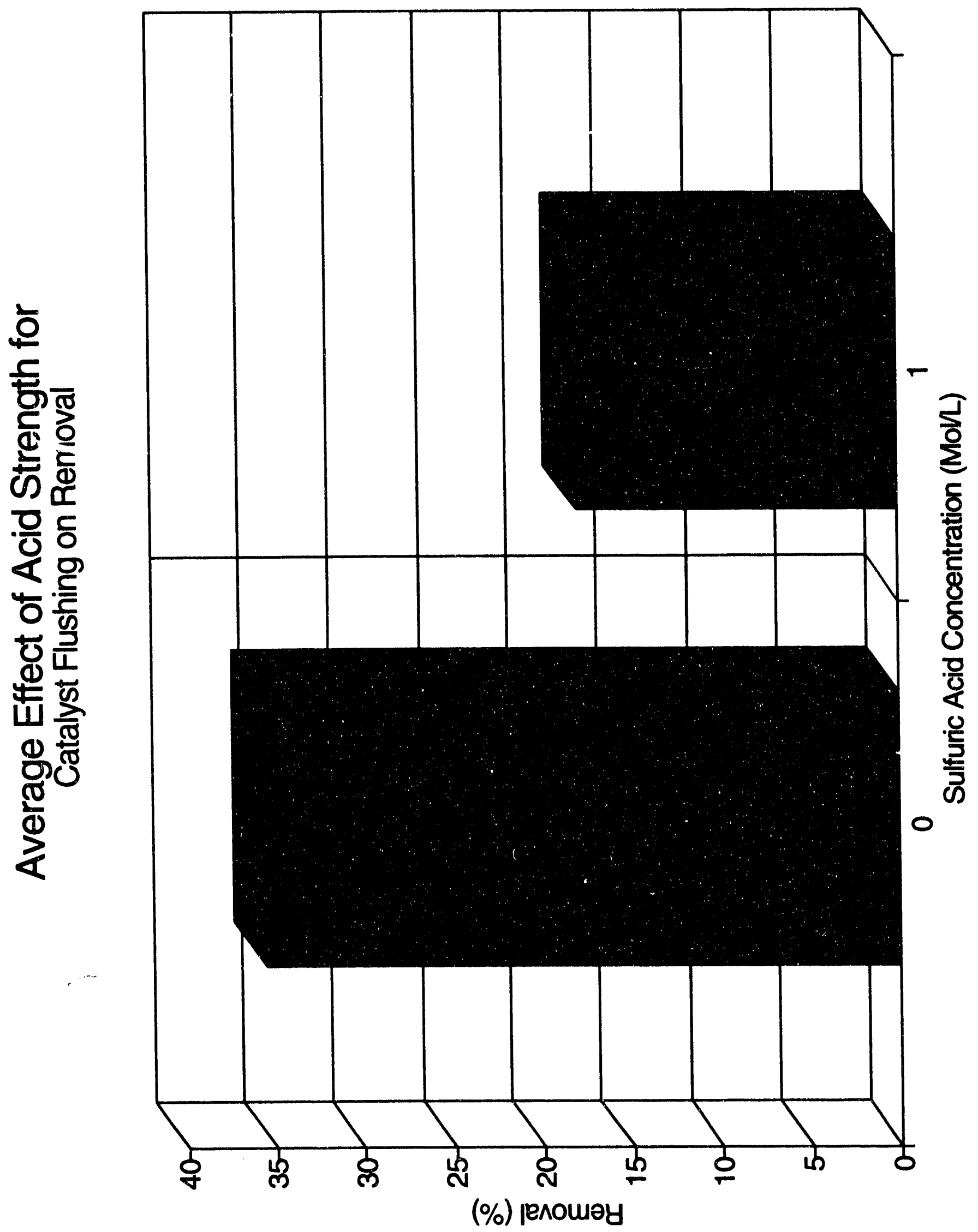




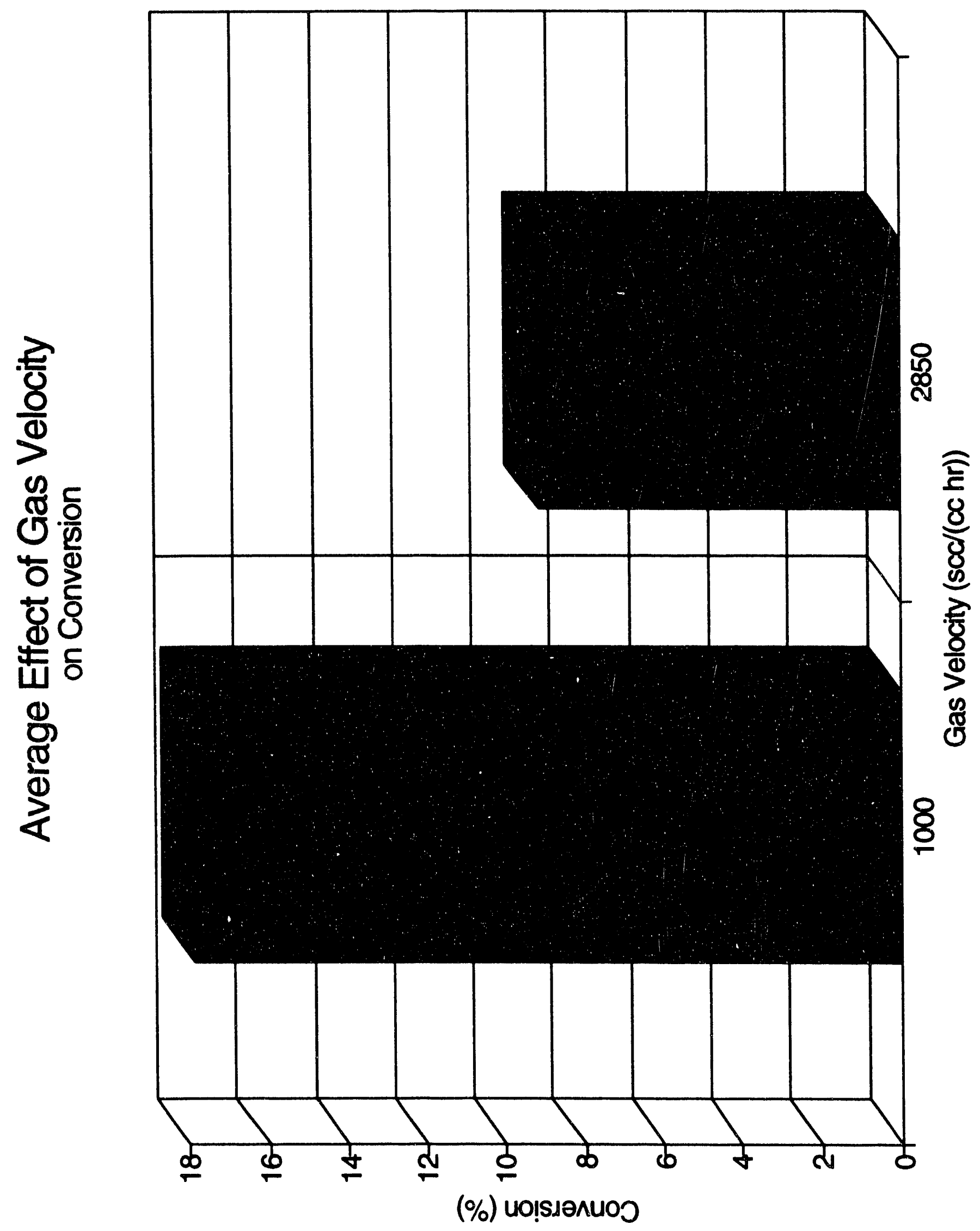




\section{Sulfurous Acid Concentration Present in the Product}

Single Factor Effects

$\mathrm{V}_{\mathrm{B}} \quad$ - increasing the gas velocity increases the amount of sulfurous acid in the product. (Figure 7)

$V_{1} \quad$ - increasing the superficial liquid velocity decreases sulfurous acid concentration in the product due to increased dilution. (Figure 8)

$\tau \quad$ - increasing the period reduces the suifurous acid concentration. (Figure 9) This is probably because the increased time without the liquid phase liquid phase increases the amount of $\mathrm{SO}$, converted to $\mathrm{SO}_{3}$ on the catalyst surface.

A - increasing the liquid phase acid strength decreases sulfurous acid concentration. (Figure 10)

Two Factor Effects

$\tau, \mathrm{A} \quad$ - to minimize sulfurous acid concentration a long period with high liquid phase acid strength is favoured

\section{Sulfuric Acid Concentration in the Product}

Single Factor Effects

$V_{1} \quad$ - increasing the liquid superficial velocity reduces the sulfuric acid concentration. (Figure 11) This is due to dilution.

Two Factor Effects

$\tau, \mathrm{V}_{\mathbf{l}}$ - to maximize the sulfuric acid concentration it will be necessary to increase the period and reduce the liquid superficial velocity.

From the above results it appears that the objectives of removal and conversion to sulfuric acid are at cross purposes. However, since marketability of the sulfuric acid product is paramount to the usefulness of this process conversion is the more significant factor. Removal however can be increased by using a deeper reactor bed. For all future experiments the a period of 30 minutes will be used. This approach will also increase the concentration of sulfuric acid in the product compared to the concentration of sulfurous acid.

Since we can increase the product acid strength over the $2 \mathrm{~N}$ sulfuric acid used to flush the catalyst we can conclude that at least $2 \mathrm{~N}$ acid strengths can be achieved using this process. In fact RTI has demonstrated even higher acid strengths can be achieved. As part of our future work we will also go to acid concentrations as high as $10 \mathrm{~N}$. 


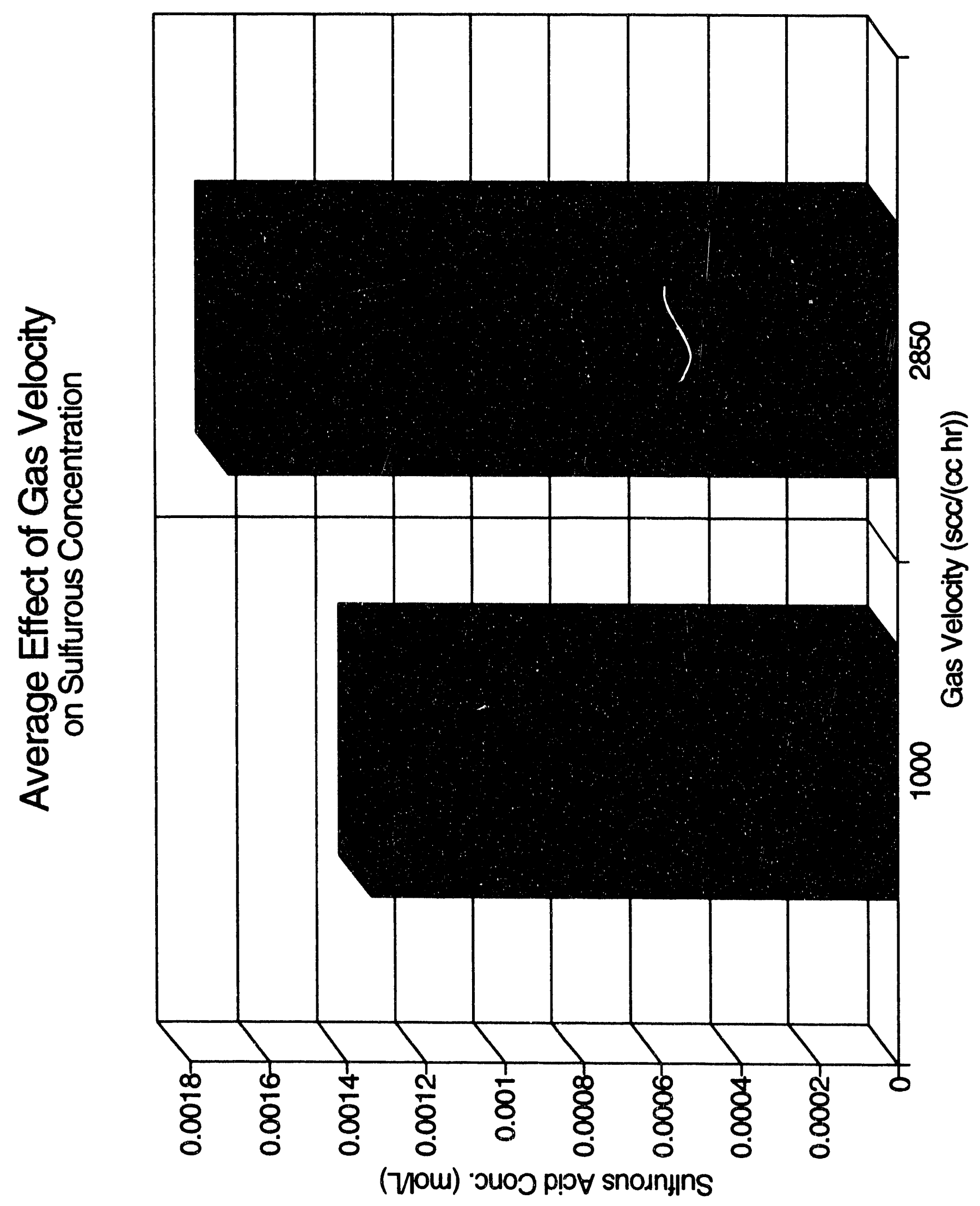




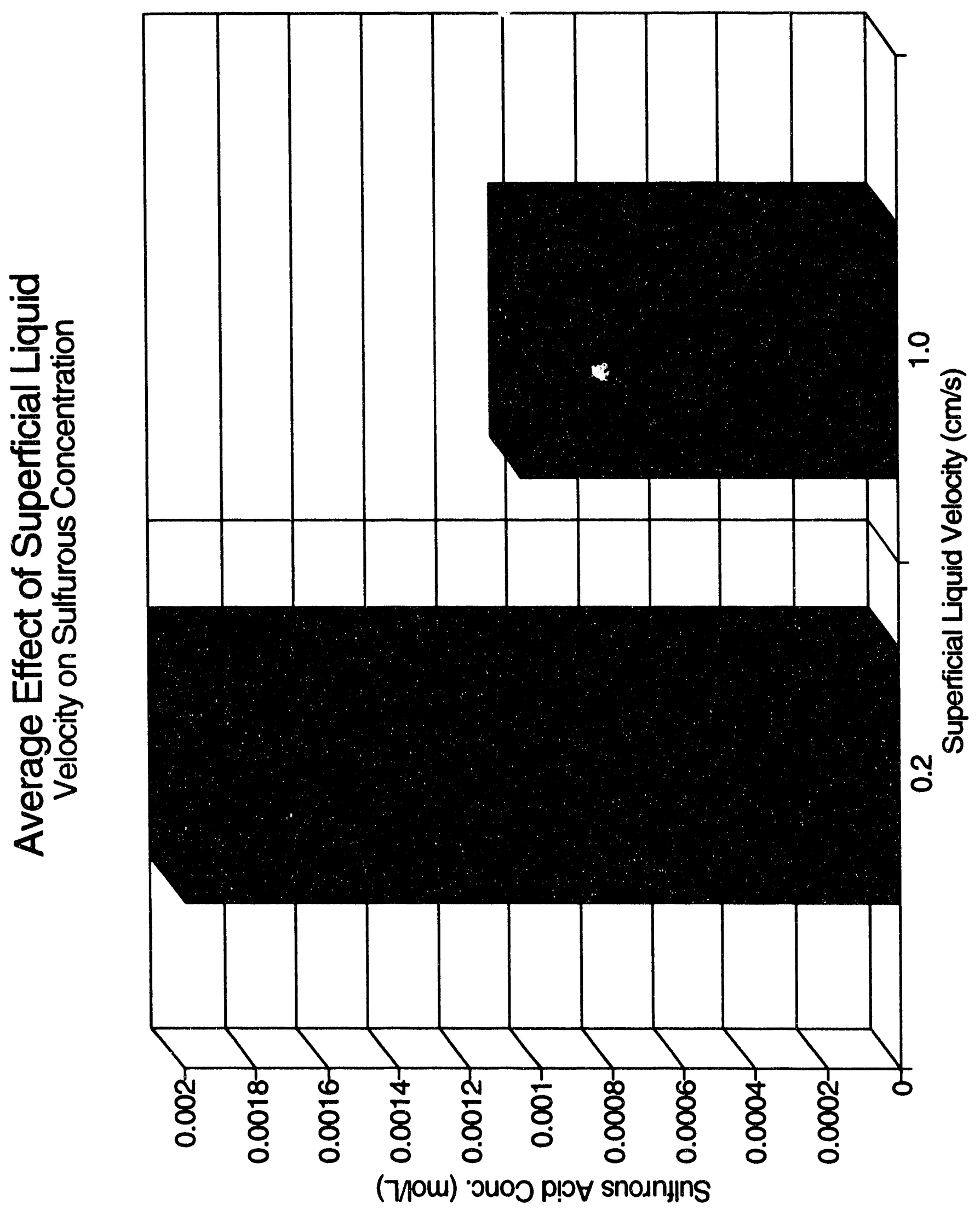




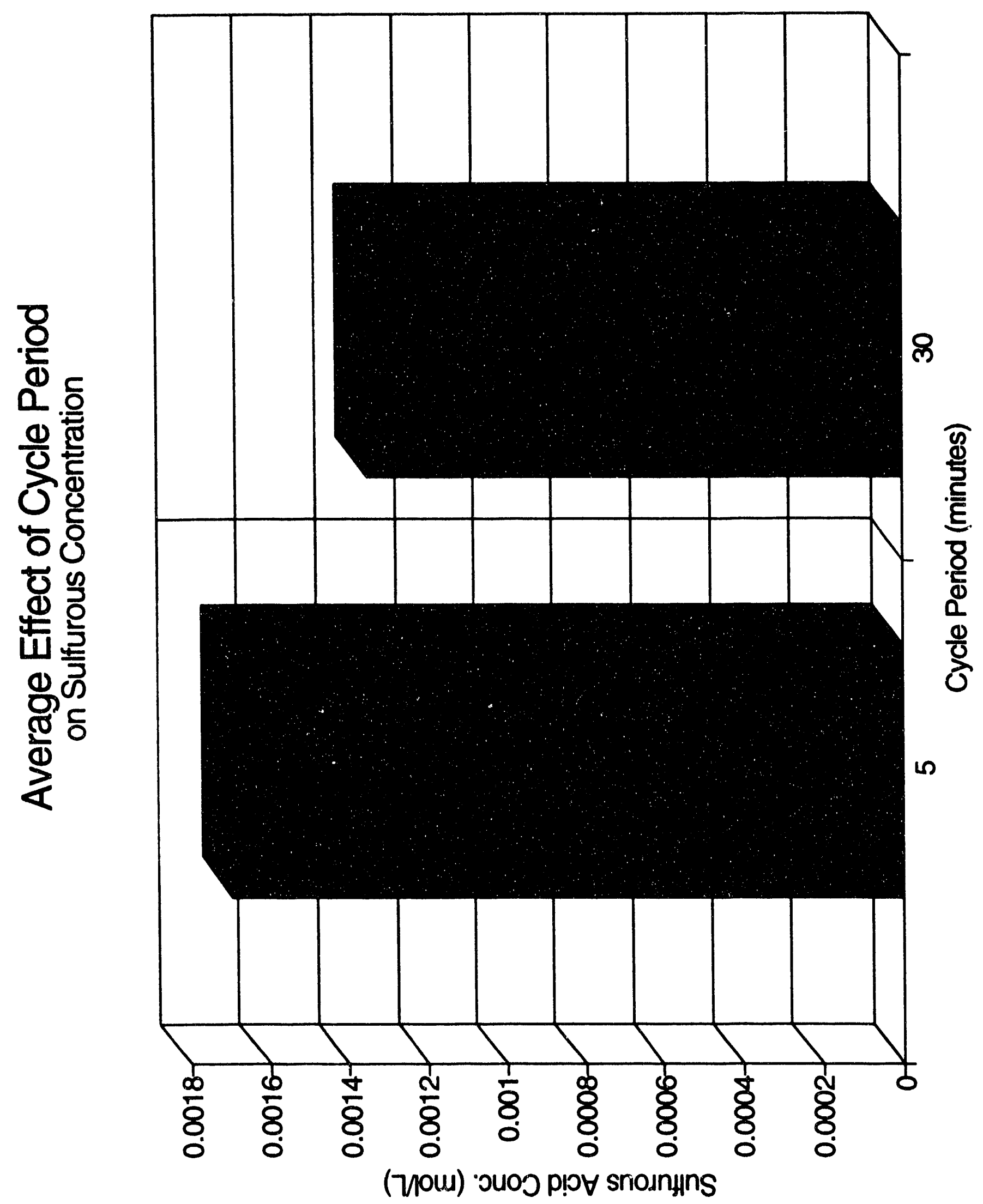




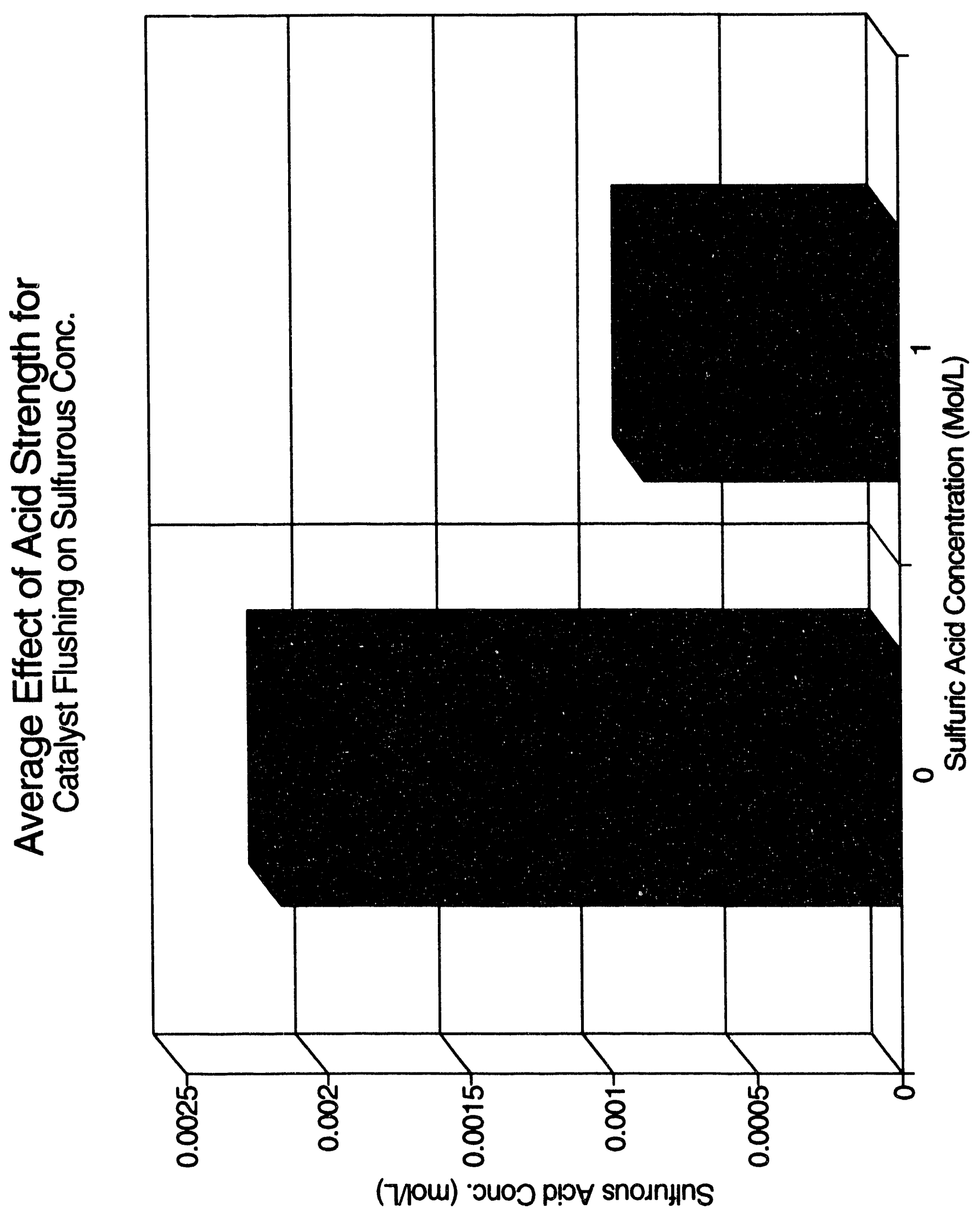




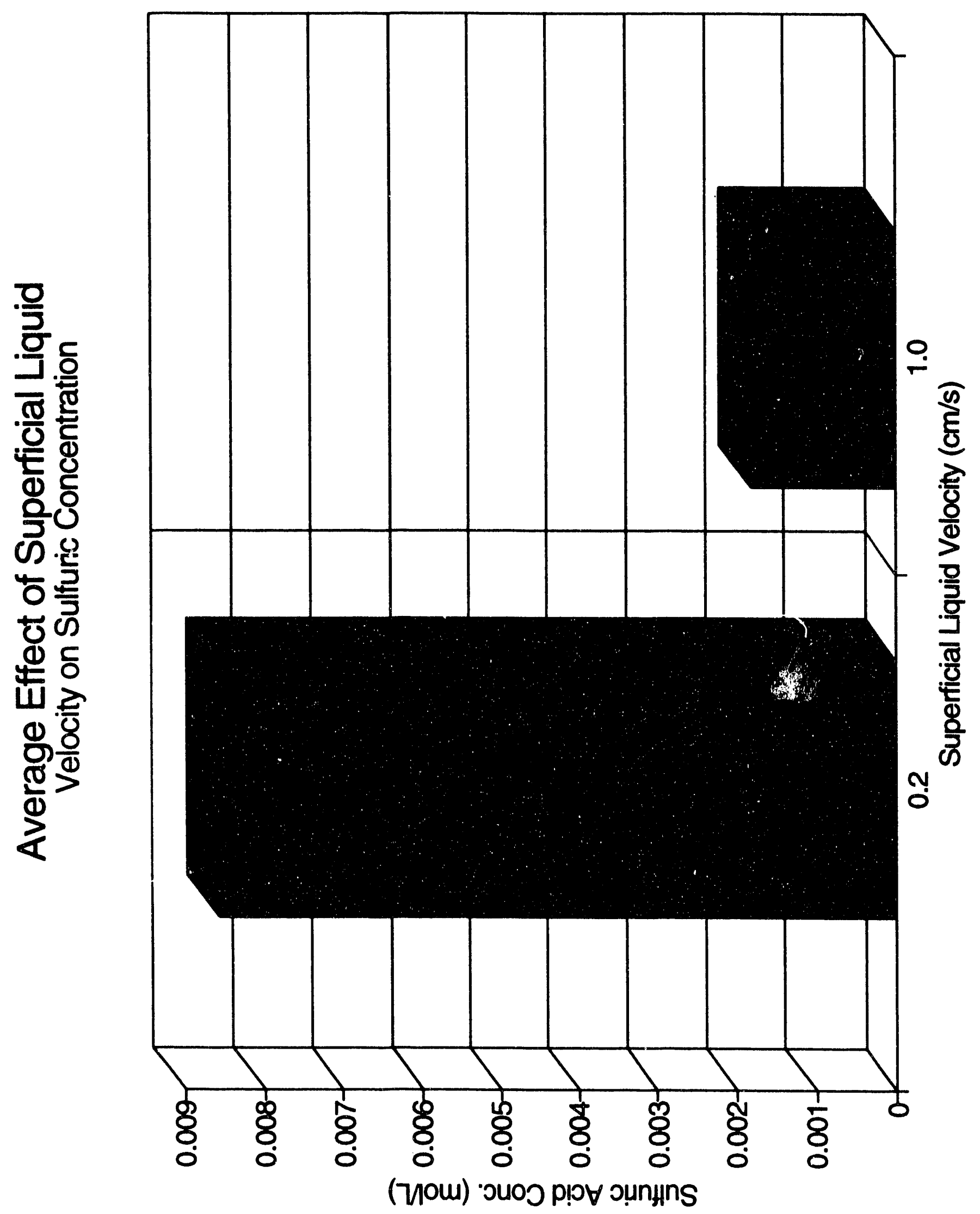


Initial calculations have been completed to predict the required bed height and the reactor $\Delta \mathrm{P}$ for $95 \% \mathrm{SO}_{2}$ removal. The average for all the experiments in the factorial design were a bed height of $134 \mathrm{~cm}$ and dry $\Delta \mathrm{P}$ of $212 \mathrm{~Pa}$. To achieve $95 \% \mathrm{SO}_{2}$ removal at a gas velocity of 2850 $\mathrm{scc}^{\bullet} \mathrm{cc}^{-1} \bullet \mathrm{hr}^{-1}$, period of 30 minutes, flush liquid acid strength of $1 \mathrm{M}$, superficial liquid velocity of $0.2 \mathrm{~cm}^{\circ} \mathrm{s}^{-1}$ and a flush duration of 0.5 minutes the reactor bed would be $380-611 \mathrm{~cm}$ high and have a dry pressure drop of $438-707 \mathrm{~Pa}$. This was done to calculate the absolute maximum pressure drop and bed height for this process. It should be noted however that all these results are at a bed temperature of $21{ }^{\circ} \mathrm{C}$ and we do not expect an industrial application at this temperature. Experiments done at RTI indicate that $95 \%$ removal can be achieved quite easily at $80^{\circ} \mathrm{C}$ and we will also run experiments at these conditions in a continuous mode.

\subsection{WORK PROGRESS FOR THE PAST QUARTER}

The major problem to note this quarter was a loss of accuracy in the total acidity determinations. The accuracy of our auto-titrator is $\pm 0.05 \mathrm{ml}$. When we were using deionized water as the flushing liquid and $0.1 \mathrm{~N} \mathrm{NaOH}$ to titrate the accuracy was excellent. This was verified by comparing the removal based on wet chemistry and the removal based on the ultraviolet $\mathrm{SO}_{2}$ gas analyzer. However, when the flushing liquid was changed to $2 \mathrm{~N}$ sulfuric acid we had to use $1 \mathrm{~N} \mathrm{NaOH}$ to titrate in order to keep the quantity of titrant at a manageable level. These two factors reduced the accuracy of our total acidity determinations. To correct for this I used the ultra-violet gas analyzer results to calculate removal. The quantity of sulfuric acid created in the product could then be determined based on the removal and subtracting the quantity of sulfurous acid present in the product. The sulfurous acid titration does not appear to have been affected by the increase in the flushing liquid acid strength. 


\subsection{WORK PLANNED FOR NEXT QUARTER}

\section{$2.1 \mathrm{SO}_{2}$ REMOVAL}

After completion of the current factorial design we will run experiments at higher temperatures $\left(80^{\circ} \mathrm{C}\right)$ using the BPL activated carbon to see if there is an improvement in removal, conversion and sulfuric acid concentration. We will also test the MCCI carbon at the higher temperature for extended periods to see if there is any reduction in removal as seen in the BPL Carbon at low temperatures. Modifications to the equipment are currently underway in order that we can operate at increased temperatures. Table 3 shows the levels of the variables to be studied in the next quarter.

Table 3: Levels of Variables studied in Factorial Experiments at $80^{\circ} \mathrm{C}$

\begin{tabular}{|c|c|c|}
\hline Variables & Low Value "-" & High Value "+" \\
\hline 1-Space Velocity $\left(V_{1}\right)$ & $1000 \mathrm{cc}^{\circ} \mathrm{cc}^{-1} \cdot \mathrm{hr}^{-1}$ & $2850 \mathrm{cc}^{\prime} \mathrm{cc}^{-1} \bullet \mathrm{hr}^{-1}$ \\
\hline $\begin{array}{c}\text { 2-Liquid Velocity }\left(\mathrm{V}_{8}\right) \\
\text { (superficial) }\end{array}$ & $0.2{\mathrm{~cm} \cdot \mathrm{s}^{-1}}^{-1}$ & 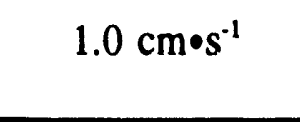 \\
\hline 3-Flush Duration(D) & 0.5 minutes & 3 minutes \\
\hline 4-Catalyst(C) & BPL & MCCI \\
\hline 5-Flush Liquid(A) & Deionized Water & $2.0 \mathrm{~N} \mathrm{H}_{2} \mathrm{SO}_{4}$ \\
\hline
\end{tabular}



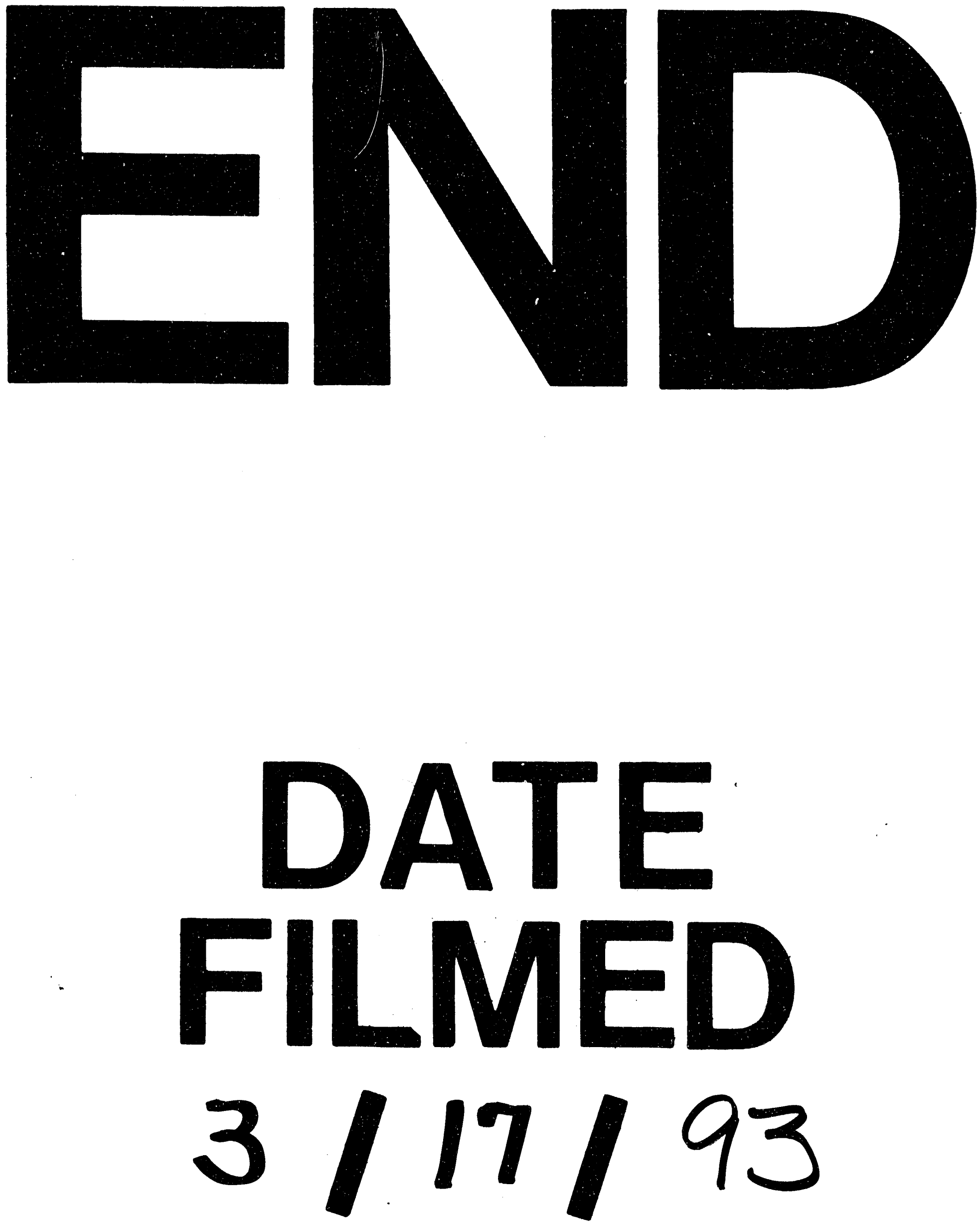

1 
